\title{
Free radical products in X-irradiated Rochelle salt: low temperature ENDOR and DFT studies
}

Einar Sagstuen, Eli Olaug Hole and Anders Lund

\section{Linköping University Post Print}

N.B.: When citing this work, cite the original article.

Original Publication:

Einar Sagstuen, Eli Olaug Hole and Anders Lund, Free radical products in X-irradiated Rochelle salt: low temperature ENDOR and DFT studies, 2012, Radiation Physics and Chemistry, (81), 2, 168-179.

http://dx.doi.org/10.1016/j.radphyschem.2011.10.001

Copyright: Elsevier

http://www.elsevier.com/

Postprint available at: Linköping University Electronic Press

http://urn.kb.se/resolve?urn=urn:nbn:se:liu:diva-74636 


\title{
Free Radical Products in X-Irradiated Rochelle Salt: Low Temperature ENDOR and DFT Studies
}

\author{
Einar Sagstuen ${ }^{\mathrm{a}^{*}}$, Eli Olaug Hole ${ }^{\mathrm{a}}$ and Anders Lund ${ }^{\mathrm{b}}$
}

${ }^{a}$ Department of Physics, University of Oslo, P.O. Box 1048 Blindern, N-0316 Oslo, Norway; ${ }^{\mathrm{b}}$ Department of Physics, Chemistry and Biology, IFM, Linköping University, S-581 83 Linköping Sweden.

*Corresponding author. Tel.: +47 228 56430, Fax.: +47 22856422

E-mail address: einar.sagstuen@ fys.uio.no (E. Sagstuen). 


\section{Abstract}

Single crystals of Rochelle salt, $\left[{ }^{-} \mathrm{OOC}-\mathrm{CHOH}-\mathrm{CHOH}-\mathrm{COO}^{-}, \mathrm{Na}^{+}, \mathrm{K}^{+}\right] \cdot 4 \mathrm{H}_{2} \mathrm{O}, \mathrm{X}-$ irradiated at $10 \mathrm{~K}$, have been examined using EPR, ENDOR and EIE spectroscopic techniques to characterize the radiation induced radicals stable at that temperature and their reactions upon warming. The one-electron gain product was observed and from the hyperfine interaction with a $\beta$-proton it was unambiguously centred at the $\mathrm{C}_{4}$ position of the tartrate moiety. An additional nearly isotropic hyperfine structure of about $21 \mathrm{MHz}$ was tentatively assigned to interaction with a sodium ion exhibiting a close contact to $\mathrm{O}_{3}$ in the crystal. Evidence was obtained that the one-electron reduced radical had become protonated at one of the $\mathrm{C}_{4}$ bonded carboxyl oxygens, most probably $\mathrm{O}_{4}$. No evidence for the corresponding $\mathrm{C}_{1^{-}}$ centred reduction product was found. Two resonance lines (R2, A1) were shown by EIE to belong to a species formed by decarboxylation at $\mathrm{C}_{3}$, a secondary oxidation product. Two other resonance lines (K1, K2) were assigned to two varieties of another decarboxylation radical, centred at $\mathrm{C}_{2}$, distinguished by differences in the potassium ion coordination. Furthermore, one other resonance line (A2) was tentatively ascribed to a third decarboxylation radical, centred at the opposite end of the tartrate moiety. The precursor of these products, that is, the one-electron loss product, was not observed after X-irradiation at $10 \mathrm{~K}$. Thermally induced free radical reactions followed by EPR in the temperature range 12 to $119 \mathrm{~K}$ indicate that a water molecule or a hydroxyl ion is eliminated from the one-electron reduction product radical and that $\mathrm{C}_{3}$-centred radical is formed. The reduction and oxidation reaction pathways of hydroxy acid derivatives are discussed.

Keywords: Rochelle salt, tartaric acid, hydroxy acid radicals, ionizing radiation, EPR spectroscopy, ENDOR. 


\section{Introduction}

The radiation induced free radical chemistry of dicarboxylic acids, among them tartaric acid $(\mathrm{HOOC}-\mathrm{CHOH}-\mathrm{CHOH}-\mathrm{COOH})$, and their salts, has received attention for several decades (Iwasaki, 1972; Box, 1977). The Rochelle salt, being the Na, K-salt of tartaric acid, is of particular interest as it exhibits ferroelectricity in the solid state (Solans et al., 1997). The nature of the radicals formed in Rochelle salt was investigated to obtain some understanding of the mechanisms producing changes in the ferroelectric properties of this compound upon irradiation (Moulton and Moulton, 1961; Suzuki and Abe, 1967; Suzuki and Abe, 1968; Suzuki, 1974; van Treek and Windsch, 1977).

More recently, the actual nature of the radiation-induced radicals in tartrates has evoked more general interest because of the possible application of ammonium tartrate in Electron Paramagnetic Resonance (EPR) solid-state dosimetry (Olsson et al., 1999; Olsson et al., 2000; Kolbun et al., 2010). The radicals stable at room temperature in this system were previously identified using Electron-Nuclear Double Resonance (ENDOR) (Brustolon et al., 1996). The radicals observed at room temperature are, however, not those initially formed but created by secondary radical reactions from primary oxidation and reduction products (Iwasaki, 1972; Box, 1977).

Until now, the nature of these reactive primary radicals has not been clarified with certainty in tartaric acid salts, contrary to the case with the pure acid. Thus, dl-tartaric acid has been examined previously by ESR and ENDOR (Moulton and Cernansky, 1969; Moulton and Cernansky, 1970; Mulchinock and Hallett, 1972; Moulton and McDearmon, 1980). Primary oxidation products, like the alkoxy radical, were not observed even at $4.2 \mathrm{~K}$. A radical formed in a deuterated crystal was assigned to the decarboxylated radical DOOC$\mathrm{CH}(\mathrm{OD})-\dot{\mathrm{C}} \mathrm{H}(\mathrm{OD})$ assumedly formed in the oxidation pathway of decay reactions. This assignment was based on the observed ENDOR spectrum exhibiting a resonance due to an $\alpha$ - 
proton interaction. Hyperfine structure due to interactions with $\beta$-protons was not observed at 4.2 K, but became apparent in a structure stable at $188 \mathrm{~K}$. The reduction product was an anion radical with the unpaired electron at the carboxylic group and exhibiting hyperfine coupling to a $\beta$-proton. The anion decay mechanism could not be established with certainty, since secondary radicals could not be identified, but loss of $\mathrm{CO}_{2}^{-}$was considered most likely. However, a different decay mechanism involving water elimination from protonated oneelectron reduction products was more recently suggested for the Rochelle salt and for other salts of tartaric acid (Samskog et al., 1978; Samskog et al., 1979). The kinetics of reduction radical decay and the growth of the secondary $\mathrm{RCHCOO}^{-}$radical were measured both by pulse radiolysis and by EPR.

The purpose of the present work is to further investigate the formation of these primary radical products and to study their transformation to more stable species in the Rochelle salt, using equipment specially designed for in situ low temperature irradiation and single crystal EPR/ENDOR measurements (Øhman et al., 2006), complemented by analyses of the corresponding ENDOR-Induced EPR (EIE) spectra. The correct assignment of radical structures was not always obvious from the experimental EPR, ENDOR and EIE data. The assignment issue was therefore also addressed using density functional theory (DFT)-type quantum chemical calculations. Additional calculations were made concerning the nature of the previously studied radicals at room temperature (Moulton and Moulton, 1961; Suzuki and Abe, 1967; Suzuki and Abe, 1968; Suzuki, 1974; van Treek and Windsch, 1977).

\section{Crystal and molecular structure}

Rochelle salt is the tetrahydrate $\mathrm{Na}^{+}, \mathrm{K}^{+}$-salt of tartaric acid, as shown in Scheme 1 together with the numbering system adopted in the present work. A preliminary crystal structure was published by Beevers and Hughes (Beevers and Hughes, 1941). Several 
refinements of this structure have occurred, also by neutron diffraction (Solans et al., 1997), but to our knowledge no complete and error-free revised structure has been published until Görbitz and Sagstuen did a full X-diffraction analysis of the structure to an R-value of 0.028 at $105 \mathrm{~K}$ (Görbitz and Sagstuen, 2008).

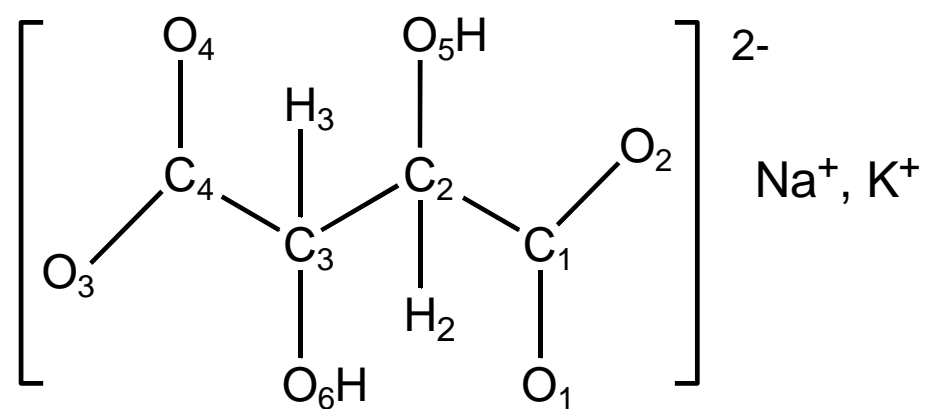

Scheme 1. The Rochelle salt

An important feature of the structure is that the asymmetric unit contains one sodium and one potassium ion. The potassium ion, however, occupies one out of two possible and different positions in the cell, each with $50 \%$ occupancy. These positions have been designated $\mathrm{K}_{1}, \mathrm{~K}_{2}$ in Scheme 2 below. An inspection of the crystal structure reveals that the two carboxyl groups exhibit very different coordinations to the metal ions and to hydrogen bonded water molecules $\left(\mathrm{O}_{\mathrm{w}}\right)$.

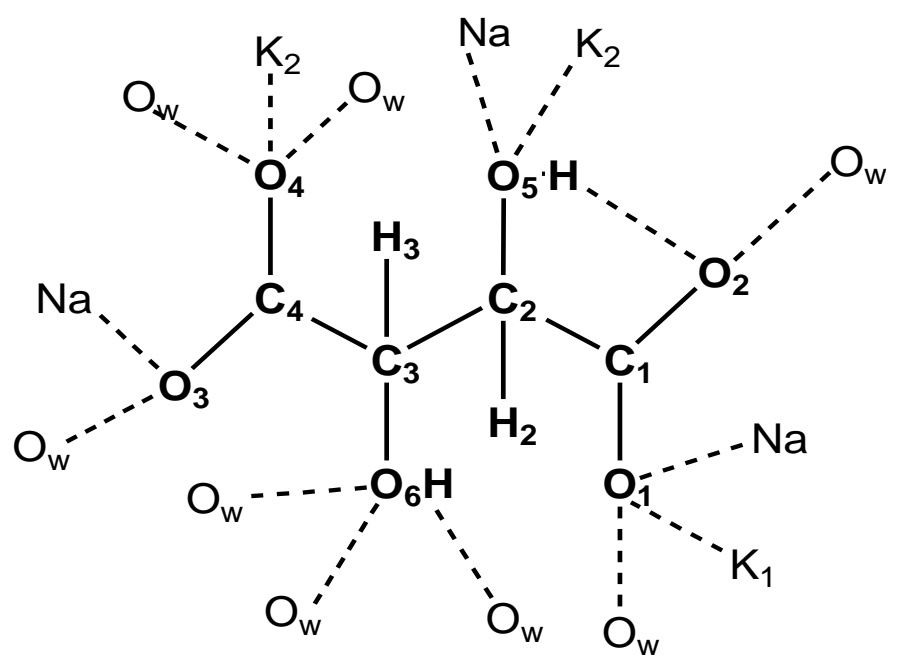

Scheme 2. Rochelle salt carboxyl group coordination 
In the $-\mathrm{C}_{1} \mathrm{O}_{1} \mathrm{O}_{2}$ carboxyl group, oxygen $\mathrm{O}_{1}$ participates in the two shortest contacts to metal ions, $\mathrm{Na}$ and $\mathrm{K}_{1}$ (2.35 and $2.82 \AA$, respectively). In addition, $\mathrm{O}_{1}$ exhibits one water contact. The other oxygen $\left(\mathrm{O}_{2}\right)$ is coordinated to water and participates in a long intramolecular hydrogen bond to $\mathrm{H}\left(\mathrm{O}_{5}\right)$. In the $-\mathrm{C}_{4} \mathrm{O}_{3} \mathrm{O}_{4}$ group, $\mathrm{O}_{3}$ participates in contacts to $\mathrm{Na}(2.45 \AA)$ and water and $\mathrm{O}_{4}$ participates in a short contact to $\mathrm{K}_{2}(2.84 \AA)$ in addition to contacts to two water molecules. While $\mathrm{O} 5$ appears only to be weakly $\mathrm{H}$-bonding to $\mathrm{O}_{2}, \mathrm{O}_{5}$ participates in two relatively short contacts to $\mathrm{K}_{2}$ and $\mathrm{Na}$ (2.98 and $2.47 \AA$, respectively). The chain of four carbon atoms forms a plane, and the planes of the two $\mathrm{COO}^{-}$groups are twisted about $61^{\circ}$ $\left(\mathrm{C}_{1} \mathrm{OO}\right)$ and $72^{\circ}\left(\mathrm{C}_{4} \mathrm{OO}\right)$ with respect to that plane so that the angle between the two $\mathrm{COO}$ planes is about $47^{\circ}$ (Scheme 3$)$.

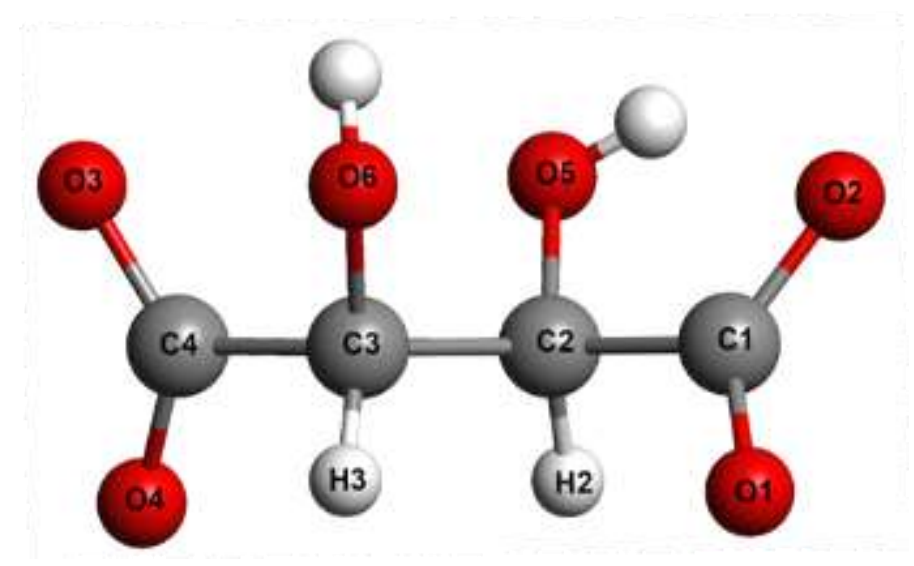

Scheme 3. Backbone configuration of the Rochelle salt

In the ferroelectric phase between $-18{ }^{\circ} \mathrm{C}$ to $24{ }^{\circ} \mathrm{C}$ the crystals are monoclinic, whereas in the non-polar phases they are orthorhombic, space group $\mathrm{P} 2{ }_{1} 2{ }_{1} 2$, with the needle axis along $\langle\mathrm{c}\rangle$.

\section{Experimental}

Rochelle salt was obtained from Sigma-Aldrich and tetrahydrate crystals were grown from saturated aqueous solutions or from $99.8 \% \mathrm{D}_{2} \mathrm{O}$ by repeated crystallizations. The crystals were mounted on the goniometer head of a Weissenberg X-ray diffraction camera. Using oscillation diagrams, the selected crystal axis was aligned with the rotation axis within 
$1^{\circ}$. The crystal was then transferred and glued (TraCon silver epoxy) onto the tip of the copper pedestal of an Air Products cold finger cryostat without loss of alignment. The cryostat was then inserted into the vacuum shield of the X-band cavity. The crystal was positioned immediately above the cavity next to a thin $(0.2 \mathrm{~mm})$ aluminum irradiation window in the vacuum shield. Before X-irradiation, the crystal was cooled to near liquid helium temperature $(\mathrm{T}<10 \mathrm{~K})$. The $\mathrm{X}$-ray dose delivered to the crystal was estimated to about $3 \mathrm{kGy}$. After irradiation, the crystal was carefully lowered into the resonance EPR/ENDOR cavity $\left(\mathrm{TM}_{011}\right)$ for EPR, ENDOR and EIE measurements. The microwave frequency was measured using an HP 5324A $40 \mathrm{GHz}$ frequency counter.

The X-band EPR, ENDOR and EIE experiments were performed using a BRUKER ESP300E spectrometer equipped with a NMR gaussmeter and the BRUKER DICE ENDOR accessory. For ENDOR and EIE, an ENI 3200L rf Power Amplifier was used. The ENDOR system was set to generate a square-wave-like frequency modulated rf-field, with modulation frequency at $12.5 \mathrm{kHz}$ and with a modulation depth of $140 \mathrm{kHz}$.

EPR and ENDOR measurements were made by rotating the cryostat containing the sample in $5^{\circ}$ intervals through $180^{\circ}$. The program MAGRES was used to derive the hyperfine coupling tensors from the ENDOR data (Nelson, 1980; Nelson and Nave, 1981). A six-parameter linear regression routine generates these tensors from the polar angles $(\theta, \varphi)$ of the rotation axes, the angle of rotation $\alpha$, and the corresponding measured ENDOR frequency. Refinements including a total of nine angles $\left(\theta, \varphi\right.$, and the starting angle $\alpha_{0}$ for each plane) were made, using a nonlinear refinement procedure converging to minimum root mean square (rms) value for the complete data set. The program KVASAT was used to simulate the single crystal EPR and EIE spectra (Sagstuen et al., 1997; Sagstuen et al., 2000). 


\section{Calculations}

Density Functional Theory (DFT) calculations were performed using the Windows parallel-version of the GAUSSIAN03 program package (Frisch et al., 2003). Both singlemolecule and cluster calculations were used. The starting geometry was obtained from the Xdiffraction data (Görbitz and Sagstuen, 2008). The single point calculations on the optimized structures and the optimization runs all used the B3LYP hybrid functional and augmented double- $\zeta 6-31 \mathrm{G}(\mathrm{d})$ basis set. The cluster used included a tartrate dianion molecule and the 8 closest water molecules, shown in Scheme 2, involved in hydrogen bonding to the tartrate dianion. The water molecular coordinates were frozen during the optimization calculations. The metal ions also indicated in Scheme 2 were, however, not included in these calculations. With the NOSYMM option, the calculated hyperfine coupling tensors were expressed in the crystallographic reference system and thus directly comparable to the experimental data.

\section{Experimental Results and Analyses}

EPR spectra obtained after irradiation and measurement at $10 \mathrm{~K}$ contained hyperfine lines spanning over a range of ca $7 \mathrm{mT}$ as seen from Figure 1. The EPR spectra were complex, evidently containing resonances due to several radicals. On the low-field side, additional weak features probably due to secondary alkoxy radicals were present. These were not analyzed further in the present work.

By contrast, the ENDOR spectra obtained at $10 \mathrm{~K}$ from partially deuterated crystals, $\left[{ }^{-} \mathrm{OOC}-\mathrm{CHOD}-\mathrm{CHOD}-\mathrm{COO}^{-}\right] \cdot \mathrm{K}^{+}, \mathrm{Na}^{+}, 4 \mathrm{D}_{2} \mathrm{O}$ revealed a number of well-resolved resonance lines with different intensities. Some ENDOR spectra are shown in Figure 2. As demonstrated in Figure 2, in the region above $22 \mathrm{MHz}$ the ENDOR spectra exhibit resonance lines due to six different proton hyperfine couplings. Two of these are typical $\beta$-type couplings and are designated R1 and R2. Two are $\alpha$-type couplings and are designated A1 
and A2. The remaining two apparently are of the $\beta$-type, but separated by only about 0.6 $\mathrm{MHz}$ they follow each other closely. The separation between them varied only slightly in the three planes. These two lines have been designated K1 and K2. An illustration of the angular behaviour of the ENDOR lines upon rotation of the crystal about the $<a>$-axis is presented in Figure 3. A slight misalignment of the crystal can be observed as a small doubling of the $\alpha$ proton lines in a limited angular region.

The hyperfine coupling tensors corresponding to ENDOR resonance lines R1, R2, A1, A2, K1 and K2 were extracted from the data and are reproduced in Table 1 together with some relevant crystallographic data.

In crystals grown from $\mathrm{H}_{2} \mathrm{O}$ solutions, a large number of lines due to the exchangeable protons of the hydroxyl groups and water of crystallization were present in the region $10-24 \mathrm{MHz}$. In particular, a line at about $22.5 \mathrm{MHz}$ for $\mathrm{B} \|<\mathrm{a}>$ was prominent in these crystals, but completely absent in crystals grown from $\mathrm{D}_{2} \mathrm{O}$ solution. Similar EIE spectra were obtained from this exchangeable coupling and the R1 coupling, however, the corresponding hyperfine coupling tensor could not be determined.

In ENDOR spectra from the partially deuterated crystals, the $10-24 \mathrm{MHz}$ frequency region is less crowded and in particular it became possible to observe one additional, very broad line, with unresolved substructure, varying only slightly with orientation around 19.5 MHz. A corresponding line with lower intensity was observed at about $11.5 \mathrm{MHz}$. These spectral features are denoted with arrows in Figure 2. The intensity of these lines was dependent upon which position of the EPR spectrum that was monitored for ENDOR, being most evident when the extreme EPR lines were saturated. This is clearly demonstrated by the ENDOR spectra in Figure 2. As will be discussed later, it is assumed that this line is due to hyperfine interaction with a sodium ion, its quadrupolar coupling being small and mainly unresolved. The coupling tensor of this ENDOR line was not determined. Uncommented 
weak spectral features between 10 and $20 \mathrm{MHz}$ could not be followed through a sufficient number of orientations to allow for any analysis.

Figure 4 shows characteristic EIE spectra obtained from the various ENDOR couplings discussed above.

\subsection{The R1 coupling}

The hyperfine coupling tensor of the $\mathrm{R} 1$ resonance line is shown in Table 1. For comparison, the crystallographic interspin vector from $\mathrm{C}_{4}$ to $\mathrm{H}\left(\mathrm{C}_{3}\right)$ is also presented. This direction deviates from the direction of the maximum $\mathrm{R} 1 \beta$-proton coupling by less than $2^{\circ}$. No other crystallographic interatomic direction fits equally well. Combined with the clear evidence for non-exchangeability of the responsible proton, it will be taken as a working hypothesis that the resonance is due to a radical localized at the $\mathrm{C}_{4}$-position, interacting strongly with the $\beta$-proton $\mathrm{H}_{3}$. From the crystallographic data it can be estimated that the dihedral angle of the $\mathrm{C}_{3}-\mathrm{H}_{3}$ bond with respect to the normal of the $\mathrm{C}_{4} \mathrm{OO}^{-}$plane is about $47^{\circ}$.

In non-deuterated crystals, a prominent ENDOR line at $22.5 \mathrm{MHz}(\mathrm{B} / /<\mathrm{a}>)$ is present and EIE links this line with R1 and the sodium coupling. No tensor has been obtained, but the resonance line is most probably caused by protonation of the radical. It is known that carboxylic acid anions most commonly become neutralized by proton transfer through a hydrogen bond to a neighbouring proton donor (Sagstuen et al., 2004).

The observed non-exchangeable $\beta$-proton isotropic coupling agrees excellently with those for other protonated carboxylic acid anions, as summarized by Iwasaki (Iwasaki, 1972), Box (Box, 1977) and Muto (Muto, 1991). Likewise, the dipolar interaction for the R1 $\beta$ proton coupling with principal values $(7.6,-2.7,-4.9) \mathrm{MHz}$ is characteristic for protonated carboxylic anions (Muto, 1991). 
The ENDOR frequency of R1 with the magnetic field parallel to $<\mathrm{b}>$ is $47.8 \mathrm{MHz}$ corresponding to a hyperfine coupling of $2.35 \mathrm{mT}$. The corresponding EIE spectrum from this $\mathrm{R} 1$ resonance line (Figure 3a) exhibits a six-line pattern that can be decomposed into a doublet coupling of approximately $2 \mathrm{mT}(56 \mathrm{MHz})$ and a quartet of about $1 \mathrm{mT}(28 \mathrm{MHz})$. The same EIE pattern was obtained from the above-mentioned broad, partly unresolved line at about 19-20 MHz, tentatively attributed to a sodium interaction. The free sodium frequency is about $3.94 \mathrm{MHz}$ and thus the ENDOR line position should correspond to a sodium coupling of about (19.5-3.94) $2 \mathrm{MHz}=31.1 \mathrm{MHz}$ or approximately $1.1 \mathrm{mT}$, in good agreement with the estimate above. This six-line resonance was analysed in a similar manner in previous papers by Samskog et al. (Samskog et al., 1978; Samskog et al., 1979). These authors in addition determined the ${ }^{13} \mathrm{C}$ hyperfine coupling tensor from the central carbon and from that, a $2 \mathrm{p}$-spin density of 0.71 at $\mathrm{C}_{4}$ could be extracted. The eigenvector for the maximum ${ }^{13} \mathrm{C}$ coupling tensor makes an angle of about $15^{\circ}$ with the $>\mathrm{C}_{4} \mathrm{OO}$ plane, supporting the assignment of the localization of the anion to $\mathrm{C}_{4}$ and not to $\mathrm{C}_{1}$.

Muto (Muto, 1991) found that protonated carboxylic acid anions regularly are nonplanar, and that the non-exchangeable $\beta$-coupling could be described using the relation

$$
\mathrm{a}_{\text {iso }}^{b} \gg r^{p} \mathrm{~B}_{2} \cos ^{2} q
$$

with $\mathrm{B}_{2}=120 \mathrm{MHz}$ if the major lobe of the unpaired electron orbital is trans to the $\mathrm{C}-\mathrm{H}_{\beta}$ bond and $60 \mathrm{MHz}$ if it is cis to this bond (see Scheme 4).

(a)

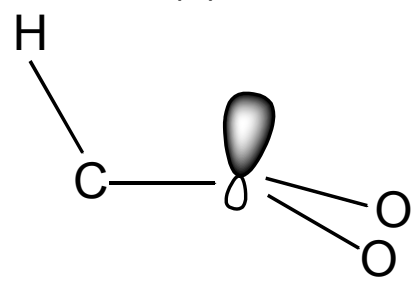

(b)

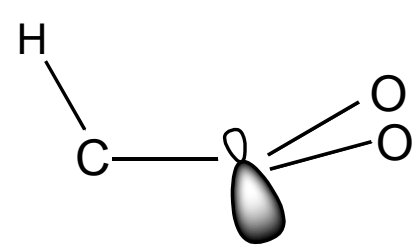

Scheme 4: (a) cis and (b) trans configurations of the lone electron orbital with respect to the $\mathrm{C}-\mathrm{H}_{\beta}$-bond 
With a $\mathrm{B}_{2}$ value of $60 \mathrm{MHz}$ and $\rho^{\pi}=0.71$, a dihedral angle of $47^{\circ}$ corresponds to a $\beta$-coupling of $20 \mathrm{MHz}$ only. Hence, from the magnitude of the observed $\beta$-coupling a trans configuration (Scheme 4b) appears more probable. Then $\mathrm{B}_{2}=120 \mathrm{MHz}$ and the estimated $\beta$-coupling becomes $40 \mathrm{MHz}$, closer (although still smaller) to the experimentally observed value. The observed anisotropy of the coupling is in excellent agreement with this type of bending (Muto, 1991; Øhman et al., 2006; Øhman and Sagstuen, 2008). Furthermore, calculations show that this type of bending will bring the eigenvector of the maximum ${ }^{13} \mathrm{C}$ coupling (Samskog et al., 1978; Samskog et al., 1979) closer to the lone electron orbital (LEO), the extent of which depends upon the degree of bending. The deviation between the observed and calculated $\beta$-coupling may be due to a non-symmetrical bending at $\mathrm{C}_{4}$, resulting in an effective reduction of the dihedral angle.

The spin density at $\mathrm{O}_{4}$ must be small since there is no discernible hyperfine interaction with the (in-plane) $2.84 \AA \mathrm{K}$-coordination at $50 \%$ population. The closest contact to $\mathrm{O}_{3}$ is a sodium ion at $2.45 \AA$ located nearly perpendicular to the $\mathrm{C}_{4} \mathrm{O}_{3} \mathrm{O}_{4}$ plane (the distance to $\mathrm{C}_{4}$ is $3.08 \AA$ ). No other sodium is as close as this to either of $\mathrm{C}_{4}, \mathrm{O}_{3}$ or $\mathrm{O}_{4}$ and hence the observed sodium coupling is tentatively assigned to this close contact. Our data suggest that the radical is protonated, this leaves it most probable that the protonation site is $\mathrm{O}_{4}$. This will result in some conjugation transfer of the spin from $\mathrm{C}_{4}$ to $\mathrm{O}_{3}$, enhancing the sodium interaction.

\subsection{The R2, A1 couplings}

The field-selected ENDOR spectra (Fig. 2) and the EIE spectra (Fig. 3) clearly couple the two resonance lines R2 and A1. At field positions where the ENDOR line R2 is strong A1 is always strong as well. The EIE is a broad doublet characteristic for the A1 coupling and with a line width that accommodates the R2 coupling. Both ENDOR lines give similar EIE 
spectra. The A2 coupling gives a broad doublet EIE (not shown) different from that above, clearly due to a radical different from that giving rise to the $\mathrm{R} 2$, A1 couplings.

The non-exchangeable $\beta$-coupling $\mathrm{R} 2$ is a typical, although relatively small, $\mathrm{C}-\mathrm{C}-\mathrm{H}_{\beta}-$ coupling. The direction for the maximum eigenvector is expected to be close to the $\mathrm{C}^{\cdots} \mathrm{H}$ interspin vector unless significant delocalization of the spin is present.

The A1 $\alpha$-coupling is fairly large. Using a $\mathrm{Q}_{\mathrm{H}}^{\mathrm{CH}}$ value of $-72 \mathrm{MHz}$ in the McConnell relation (McConnell and Chesnut, 1958; Bernhard, 1981):

$$
\mathrm{a}_{\mathrm{iso}}=\mathrm{Q}_{\mathrm{H}}^{\mathrm{CH}} r^{p}
$$

yields a spin density $\rho^{\pi}$ of about 0.68 . On the other hand, from the dipolar coupling the Gordy-Bernhard procedure (Bernhard, 1984) suggests a carbon spin density of about 0.82 . This difference suggests that the carbon atom is slightly pyramidal. Following Erling and Nelson (Erling and Nelson, 2004) an umbrella bending angle of $4-5^{\circ}$ would be sufficient to explain the differences between the apparent spin densities from the isotropic and anisotropic couplings for A1.

Radicals formed by direct $\mathrm{OH}$ abstraction or by $\beta-\mathrm{OH}$ elimination processes are normally not expected to appear at $10 \mathrm{~K}$, as this typically requires more thermal energy than available at this temperature. On the other hand, decarboxylation of a primary carboxyl oneelectron oxidation product has been shown to be a common process that often is occurring either spontaneously or by very low thermal activation (Lipfert et al., 2004; Øhman et al., 2006). Previous authors have detected formation of $\mathrm{CO}_{2}$ in irradiated Rochelle salt samples by mass spectroscopy of the gas extracted from the crystals (Samskog et al., 1978). Upon decarboxylation, a radical with an $\alpha$-coupling and (eventually) one non-exchangeable $\beta$ coupling is expected to be formed, with an accompanying reconfiguration from the initial pyramidal $\mathrm{sp}^{3}$-hybridized conformation towards the planar $\mathrm{sp}^{2}$ hybridized conformation. 
Thus, attempts were made to clarify if the radical species yielding the R2, A1 couplings could be consistent with decarboxylated one-electron oxidation products of the Rochelle salt.

If the $\mathrm{C}_{3}-\mathrm{C}_{4}$ bond is broken, the LEO axis may become oriented close to this direction. In fact, the angle of deviation between this direction and the direction of the intermediate principal value of A1 (expected to be the direction of the LEO in planar $\alpha$ carbon centres) is only $4^{\circ}$. The minimum $\alpha$-proton coupling is expected to be along the $\mathrm{C}-\mathrm{H}_{\alpha}$ bond direction, also in pyramidal centres (Erling and Nelson, 2004). The crystallographic $\mathrm{C}_{3^{-}}$ $\mathrm{H}_{3}$ bond direction is $12^{\circ}$ from that of the minimum coupling. Furthermore, the direction for the maximum $\beta$-proton coupling deviates about $35^{\circ}$ from the $\mathrm{C}_{3}-\mathrm{H}_{2}$ interspin direction. These observations indicate that if the radical is formed by decarboxylation at $\mathrm{C} 3$, some minor relocation of the atoms have taken place upon bond break and partial rehybridization. Any geometric reorganization at the radical centres must represent a compromise between the tendency to attain the optimum $\mathrm{sp}^{2}$ hybridization, the possibility to stabilize the structure by retaining or forming inter- and/or intramolecular hydrogen bonds and the geometric and coulombic constraints of the environment. Finally, the dihedral angle of the crystallographic $\mathrm{C}_{2}-\mathrm{H}_{2}$ bond with respect to the direction of the intermediate principal value of $\mathrm{A} 1$ is about $65^{\circ}$ so that some $\beta$-proton coupling might well be observable, consistent with the modest R2 $\beta$-coupling.

It is concluded that the experimental evidence is consistent with the interpretation that the radical yielding the $\mathrm{R} 2$, A1 couplings may be assigned to the radical obtained by decarboxylation at the $\mathrm{C}_{4}$ end of the primary oxidation product, formed by one-electron loss of the tartrate moiety.

\subsection{The K1, K2 couplings}


The K1 and K2 couplings most probably arise by interaction with a non-exchangeable proton in two similar radicals with slightly different conformations. There are only two nonexchangeable protons in the Rochelle salt, therefore the observed couplings must be due to either $\mathrm{H}_{2}$ or $\mathrm{H}_{3}$. A clue to the minor differences in coupling constants may be provided by the potassium ion-coordinations. If $\mathrm{O}_{1}$ interacts with a $\mathrm{K}$ ion, $\mathrm{O}_{4}$ and $\mathrm{O}_{5}$ do not and vice versa, due to the $50 \%$ population of the $\mathrm{K}_{1}$ and $\mathrm{K}_{2}$ sites.

Due to the Schonland ambiguity (Schonland, 1959; Vrielinck et al., 2008), there are two possible forms of each of the $\mathrm{K} 1$ and $\mathrm{K} 2$ tensors. One appears as a $\beta$-type interaction with a large negative isotropic value whereas the other exhibits the characteristics of a small $\alpha$-type coupling (as listed in Table 1). The present experiments do not provide any clues to the distinction between these alternatives, however, proton $\beta$-type interactions with such large negative values are unknown in organic radicals and this alternative is therefore dismissed.

The number of feasible radical model that can account for the $\mathrm{K} 1$, K2 coupling tensors is also limited by the experimental temperature at which the $\mathrm{K} 1, \mathrm{~K} 2$ radicals are observed, $10 \mathrm{~K}$, which significantly restricts the possibilities for larger chemical or structural changes during radical formation. To account for the isotropic and dipolar couplings for the $\mathrm{K} 1$ and $\mathrm{K} 2$ tensors (Table 1) radical structures with extended spin delocalization over several atoms possibly including oxygen were considered. In contrast to the situation with the protonated one-electron reduction radical and the decarboxylated radical species above, an assignment based solely on experimental data for the $\mathrm{K} 1$ and $\mathrm{K} 2$ couplings proved difficult. An analysis was therefore attempted by comparing experimental and theoretical values of the isotropic and anisotropic hyperfine coupling constants for a series of candidate radical structures by DFT calculations. Thus, the assignment to a $\mathrm{C}_{2}$-centred, partially decarboxylated radical, $\mathrm{OOC}_{1} \cdots \dot{\mathrm{C}}_{2} \mathrm{H}(\mathrm{OH})-\mathrm{C}_{\beta} \mathrm{H}(\mathrm{OH})-\mathrm{C}_{4} \mathrm{OO}$ - was arrived at (for details, see section 6.3). This species may form by one-electron oxidation of the tartrate moiety, followed 
by a spontaneous lengthening of the $\mathrm{C}_{1}-\mathrm{C}_{2}$ bond, but with the $\mathrm{CO}_{2}$ group still trapped sufficiently close to the radical that considerable amounts of the spin density remain on the oxygen atoms. There are other examples in the literature on decarboxylated carboxyl cations where the abstracted $\mathrm{CO}_{2}$ group trapped in the lattice significantly influences the spectral properties of the radical (Toriyama and Iwasaki, 1976; Øhman and Sagstuen, 2008). Further discussion of this species is given in section 6.3.

\subsection{The A2 coupling}

The A2 a-coupling exhibits a smaller isotropic value than A1, but the dipolar coupling is similar. For the corresponding hyperfine coupling tensor, the McConnell relation yields a spin density of about 0.57 , whereas the dipolar coupling indicates a $2 p$-spin density of 0.79 . Thus, also in this case the carbon atom carrying the major part of the spin is pyramidal, apparently somewhat more than for A1. Again following Erling and Nelson (Erling and Nelson, 2004) an umbrella bending angle of about $8^{\circ}$ would be sufficient to explain the differences between the apparent spin densities from the isotropic and anisotropic couplings A2.

Considering the fully decarboxylated radical of the one-electron oxidized tartrate moiety at $\mathrm{C}_{2}$, the data given in Table I show that the deviation of the direction of the intermediate principal value for $A 2$ from the $\mathrm{C}_{1}-\mathrm{C}_{2}$ bond direction is $37^{\circ}$. The crystallographic $\mathrm{C}_{2}-\mathrm{H}_{2}$ bond direction is about $24^{\circ}$ from the minimum A2 coupling. The reduced isotropic value of $\mathrm{A} 2$ as compared to $\mathrm{A} 1$ indicates that in this case more extensive bending at the radical site must occur. However, the dihedral angle of the $\mathrm{C}_{3}-\mathrm{H}_{3}$ bond direction with respect to the direction of the intermediate principal value of $\mathrm{A} 2$ is only $25^{\circ}$ so that the $\beta$-proton coupling may become larger than for the $\mathrm{A} 1, \mathrm{R} 2$ resonance and hence 
should be observable unless geometry changes occur during radical formation that increases the dihedral angle substantially.

It has not been possible to devise any other reasonable structure for the radical responsible for coupling A2. It is therefore tentatively proposed that the radical yielding the A2 coupling is assigned to the fully decarboxylated one-electron loss tartrate moiety at the $\mathrm{C}_{1}$ end of the Rochelle salt. Observing the decarboxylation radical at two different stages of development at a temperature of $10 \mathrm{~K}$ is not unreasonable considering the spectrum of excitation energies imparted by the ionization event and carried over by the one-electron oxidized species. Further discussion of this radical will be given in the DFT section 6.4.

\subsection{Radical reactions at $\mathrm{T}>10 \mathrm{~K}$}

The decay of the primary species stabilized at $10 \mathrm{~K}$ was studied by warming the samples to a specified temperature and recording the EPR spectrum at that temperature. In some instances the samples were re-cooled to $12 \mathrm{~K}$ and measured at that temperature to ensure that the observed spectral changes were irreversible. Measurements were made at two crystal orientations using a crystal grown from $\mathrm{D}_{2} \mathrm{O}$. Some spectra obtained with the magnetic field parallel to the $\langle c\rangle$ axis are displayed in Figure 5.

Clear effects of the warming could be observed as spectral changes at temperatures above $50 \mathrm{~K}$. Below that temperature the spectra were similar to those observed at $10 \mathrm{~K}$. At $117 \mathrm{~K}$ the features observed at $10 \mathrm{~K}$ had vanished. Instead a spectrum consisting of an equiintense quartet, flanked by weaker high- and low-field lines appeared. Similar results were obtained for measurements with $\mathrm{B} \|\langle\mathrm{a}\rangle$, except that the central portion at $117 \mathrm{~K}$ now consisted of a triplet with approximate 1:2:1 intensity ratio and with an additional barely resolved structure, flanked by weaker high- and low-field lines. 
These observations are similar to those of Samskog et al. (Samskog et al., 1978) who performed an EPR single crystal study of Rochelle salt crystals irradiated at $77 \mathrm{~K}$ and warmed to $108 \mathrm{~K}$. The central spectral features of the spectra were assigned to couplings from an $\alpha$ - and a $\beta$-proton. Coupling to ${ }^{13} \mathrm{C}$ in natural abundance was also detected for this resonance and was typical for a carbon-centred $\pi$-radical. The original assignment of these features was to a decarboxylated radical (Samskog et al., 1978) but later changed to the species ${ }^{-} \mathrm{OOC}-\mathrm{CH}(\mathrm{OH})-\dot{\mathrm{C}} \mathrm{H}-\mathrm{COO}^{-}$formed by a $\beta-\mathrm{OH}$ water elimination reaction from the protonated one-electron reduced species (Samskog et al., 1979). The argument for this reassignment was the simultaneous growth of spectral features attributed to the latter species and the decay of the one-electron reduced radical spectrum.

In the present study, two distinct radicals were observed to grow in at the same temperature and at similar rates during temperature annealing, as shown in Figure 5. The assignment of the outer spectral features appearing after warming to $109-119 \mathrm{~K}$ has to date not been made and is difficult due to the overlap with the stronger central quartet/triplet features. Apparently, one or several of the decarboxylation radicals, being the other dominant species at $10 \mathrm{~K}$, are the precursors for this species. Neither are the connections with the radicals stable at room temperature (Moulton and Cernansky, 1969; Moulton and Cernansky, 1970; Mulchinock and Hallett, 1972; Moulton and McDearmon, 1980) clear at present. These issues were not pursued further in the present work.

\section{DFT calculations}

Radicals of relevance for this study are (A) the (protonated) one-electron reduced species, and (B) the secondary radical ${ }^{-} \mathrm{OOC}-\mathrm{C}_{\beta} \mathrm{H}(\mathrm{OH})-\dot{\mathrm{C}}_{\alpha} \mathrm{H}-\mathrm{COO}^{-}$formed by the decay of (A). The secondary oxidation products formed by decarboxylation of the primary oneelectron oxidation radical were also considered. Finally, some structures that have been 
identified in previous studies of tartrates irradiated at room temperature were also included in the suite of calculations.

The major results of the calculations are summarized in Tables 2 - 7. The geometries were optimised for the actual radical in the cluster of 8 frozen water molecules, all derived from the Rochelle salt crystal structure as shown in Scheme 2 (Görbitz and Sagstuen, 2008). The $\mathrm{Na}^{+}$and $\mathrm{K}^{+}$ions were not included in the calculations. These interactions will certainly affect the geometries to variable degrees, and accordingly the hyperfine coupling constants, particularly for $\beta$-hydroxyl protons. The results of the calculations should therefore at best be used for guidance and not be considered as conclusive.

\subsection{The radical ${ }^{-} \mathrm{OOC}-\mathrm{CH}(\mathrm{OH})-\mathrm{C}_{\beta} \mathrm{H}(\mathrm{OH})-\dot{\mathrm{C}}_{\alpha} \mathrm{OOH}$}

This radical structure was previously proposed as the precursor of the ${ }^{-} \mathrm{OOC}-$ $\mathrm{C}_{\beta} \mathrm{H}(\mathrm{OH})-\dot{\mathrm{C}}_{\alpha} \mathrm{H}-\mathrm{COO}^{-}$radical formed in radical reactions discussed above. The optimized structure (water molecules removed for clarity) is shown in Figure 6.

Only the radical obtained by protonation at the $\mathrm{O}_{4}$ position of the one-electron reduced tartrate moiety yielded hyperfine coupling constants and eigenvector directions in agreement with the experimental data. The bending at $\mathrm{C}_{4}$ is such that the LEO is trans to the $\beta$-proton $\left(\mathrm{H}_{4}\right)$ at $\mathrm{C}_{3}$, as predicted in section 5.1. As shown in Table 2 , the calculated ${ }^{13} \mathrm{C}$ hyperfine coupling tensor is, although too large, in reasonable agreement with the experimental isotropic value $\mathrm{A}_{\text {iso }}\left({ }^{13} \mathrm{C}\right)=229 \mathrm{MHz}$ and dipolar coupling $\mathrm{B}_{\text {aniso }}\left({ }^{13} \mathrm{C}\right)=(130$,58,-72) MHz (Samskog et al., 1978), while the theoretically estimated coupling of the $\beta$ -

proton, $43.2 \mathrm{MHz}$, is somewhat smaller than the experimental value $\mathrm{a}_{\beta}\left({ }^{1} \mathrm{H}\right)=57.68 \mathrm{MHz}$ (Table 1).

The calculated coupling to the added proton at $\mathrm{O}_{4}$ was very large, as this proton was predicted (see Fig. 6) to become located in a direction almost parallel to that of the LEO. 
However, the final position of the added proton will be critically dependent of the source of the proton and of the total intra-atomic coulombic forces acting on it. As our calculation does not include any of the many alkali metal ions embedded in the crystalline lattice and otherwise also represents a very limited cut-out of the entire lattice, this result cannot be lent credibility. The experimental value of this coupling is of the order of $20 \mathrm{MHz}$ (see ref. (Samskog et al., 1979) and the discussion on the exchangeable resonance line at $22.5 \mathrm{MHz}$ above).

\subsection{The $\mathrm{C}_{3}$-centred radical ${ }^{-} \mathrm{OOC}_{1}-\mathrm{C}_{\beta} \mathrm{H}(\mathrm{OH})-\dot{\mathrm{C}}_{\alpha} \mathrm{H}(\mathrm{OH})$}

A radical of this type may be formed by decarboxylation of the one-electron oxidized tartrate moiety. Decarboxylation can in principle occur at both sides of the molecule, here the $\mathrm{C}_{4}$ side is considered.

A pronounced pyramidal geometry about $\dot{\mathrm{C}}_{\alpha}$ was obtained by geometry optimization resulting in an unusually small $\alpha$-proton splitting with $\mathrm{a}_{\alpha}=-10.25 \mathrm{MHz}$, while the ${ }^{13} \mathrm{C}$ splitting, $202 \mathrm{MHz}$, was larger than that normally found for carbon-centred radicals. Both these features are characteristic for a large $2 \mathrm{~s}$ spin population at $\mathrm{C}_{3}$. The calculation yielded an umbrella bending angle of $16^{\circ}$, as compared to the corresponding angle in an ideal tetrahedral conformation, 19.5 . Following Erling and Nelson (Erling and Nelson, 2004), the isotropic value indicates an umbrella bending angle of about $15^{\circ}$. The calculated $\beta$-proton splitting was $\mathrm{a}_{\beta}=33.83 \mathrm{MHz}$. The optimized structure (with water molecules removed for clarity) is illustrated in Figure 7, and the results of the calculations are summarized in Table 3.

The calculated hyperfine coupling tensors given in Table 3 agree fairly well with those observed experimentally for this species. The calculations predict a larger degree of bending than what is observed experimentally, thus explaining a large part of the deviations 
between calculated and observed eigenvectors for the $\alpha$-coupling. The $\beta$-coupling is of the correct magnitude, but the eigenvector for the maximum value deviates significantly from the experimental value. The $\mathrm{H}\left(\mathrm{O}_{6}\right)$ hydroxyl coupling is predicted to become small, in comparison this coupling was not detectable in the ENDOR.

\subsection{The $\mathrm{C}_{2}$-centred, partially decarboxylated radical, ${ }^{-} \mathrm{OOC}_{4}-\mathrm{C}_{3} \mathrm{H}(\mathrm{OH})-\dot{\mathrm{C}}_{\alpha} \mathrm{H}(\mathrm{OH}){ }^{\cdots} \mathrm{CO}_{2}$}

An attempt to calculate the properties of the one-electron oxidized tartrate radical resulted in a spontaneous elongation of both $\mathrm{C}-\mathrm{CO}_{2}$ bonds, the $\mathrm{C}_{2}-\mathrm{C}_{1}$ elongation so long (1.81 $\AA$ ) that the bond must be considered broken. However, the $\mathrm{CO}_{2}$ fragment was trapped sufficiently close to $\mathrm{C}_{2}$ so that a fair amount of spin density still resided at the oxygen atoms, $17 \%$ at $\mathrm{O}_{1}$ and $14 \%$ at $\mathrm{O}_{2}$. In addition almost $20 \%$ of the spin became localized at the oxygens of the $\mathrm{C}_{4} \mathrm{OO}^{-}$carboxyl group. Only about $25 \%$ of the spin is left at $\mathrm{C}_{2}$, mainly interacting with the $\alpha$-proton at $\mathrm{C}_{2}$ and the $\beta$ proton at $\mathrm{C}_{3}$. The main results of the calculations are given in Table 4 .

The isotropic coupling of $\mathrm{H}_{\alpha}\left(\mathrm{C}_{2}\right)$ is smaller than the experimental value which may be ascribed to overestimated bending at $\mathrm{C}_{2}$. This is supported by the fact that the dipolar components (which are less sensitive to bending (Bernhard, 1984)) fit the experimental data excellently. The calculated eigenvectors are in Table 4 compared to those of $\mathrm{K} 1$ and the agreement is satisfactory, taking the incompleteness of the radical environment into consideration. Also, the calculated eigenvectors for the $\mathrm{H}_{\alpha}\left(\mathrm{C}_{2}\right)$ coupling fit the crystallographic data very well.

In the crystal, $\mathrm{O}_{1}$ participates in a short contact to the potassium ion denoted $\mathrm{K}_{1}$. However, each potassium site has an occupancy of $50 \%$. Due to the relatively large amount of spin at $\mathrm{O}_{1}$, it is possible that the hyperfine couplings denoted $\mathrm{K} 1$ and $\mathrm{K} 2$ simply represent the same radical in each of the two sites of the potassium occupancy. The positive charge of 
the potassium ion will influence the spin distribution on the $\mathrm{CO}_{2}$ group and hence the hyperfine coupling tensor from $\mathrm{H}_{\alpha}\left(\mathrm{C}_{2}\right)$.

\subsection{The $\mathrm{C}_{2}$-centred, fully decarboxylated radical, ${ }^{-} \mathrm{OO} \mathrm{C}_{1}-\mathrm{C}_{\beta} \mathrm{H}(\mathrm{OH})-\dot{\mathrm{C}}_{\alpha} \mathrm{H}(\mathrm{OH})$}

As commented above, it may tentatively be suggested that the A2 coupling is due to a fully decarboxylated product at the $\mathrm{C}_{2}$ side of the one-electron oxidized tartrate moiety. The DFT calculation on this product yielded results qualitatively similar to those for the decarboxylation at the $\mathrm{C}_{3}$ side (above) although the bending at the $\mathrm{C}_{2}$ atom is less pronounced. The agreement between the experimentally obtained eigenvectors and those obtained by the DFT calculations for the $\alpha$-proton coupling is reasonable. The calculated isotropic $\beta$-coupling is somewhat too large. If this is the correct candidate for $A 2$, then further rearrangements must take place than those predicted by the present DFT calculations. The results are summarized in Table 5.

\subsection{The $\beta$-OH elimination radical ${ }^{-} \mathrm{OOC}_{1}-\mathrm{C}_{\beta} \mathrm{H}(\mathrm{OH})-\dot{\mathrm{C}}_{\alpha} \mathrm{H}-\mathrm{C}_{4} \mathrm{OO}^{-}$}

A radical of this type was postulated to form by water elimination from the protonated anion radical in Rochelle salt (Samskog et al., 1979). The optimized geometry is nearly planar about $\dot{\mathrm{C}}_{\alpha}$. The computed value of the ${ }^{13} \mathrm{C}$ coupling is somewhat smaller than the experimental value, whereas the calculated anisotropy is larger. The computed value of the $\beta$ proton splitting, $\mathrm{a}_{\beta}=60.8 \mathrm{MHz}$ is a factor of two larger than the experimental value, 29.8 $\mathrm{MHz}$, indicating a smaller $\mathrm{C}_{\beta}-\mathrm{H}_{\beta}$ dihedral angle with respect to the normal of the $\mathrm{C}_{4} \mathrm{OO}^{-}$ plane than predicted by the calculations. The $\mathrm{H}_{\alpha}$ coupling exhibits a reasonably good agreement with the experimentally determined tensor. The calculated results are presented in 
Table 4 together with the experimental values taken from (Samskog et al., 1979). The optimized structure of the radical (with water molecules removed for clarity) is shown in Figure 8. The agreement between the experimental and DFT calculated results is reasonable taking into account the lacking alkali metal ions in the DFT model system as shown in Scheme 2, and the calculations thus yield support for the proposed radical structure.

\subsection{The room temperature radical ${ }^{-} \mathrm{OOC}-\mathrm{C}_{\beta} \mathrm{H}(\mathrm{OH})-\dot{\mathrm{C}}_{a}(\mathrm{OH})-\mathrm{COO}^{-}$}

This radical is of a type suggested to be present after irradiation at room temperature of Rochelle salt (Moulton and Moulton, 1961; Suzuki and Abe, 1968) and other tartrates (Brustolon et al., 1996). Suzuki and Abe (Suzuki and Abe, 1968) proposed the radical (designated Center No. 1) to be centred at $\mathrm{C}_{3}$, exhibiting only small hyperfine couplings to the non-exchangeable and the exchangeable $\beta$-protons (the data are reproduced in Table 5). Moulton and Moulton (Moulton and Moulton, 1961) proposed the same chemical structure for a room temperature radical called Center No. 3 but the hyperfine coupling constants were very different, suggesting a different location of the spin. In particular, the total width of the spectrum assigned to Center No. 3 was about $5 \mathrm{mT}$, or $140 \mathrm{MHz}$. Table 5 summarises the results of the DFT calculations on the two proposed radical structures $\left(\mathrm{H}\right.$-abstraction at $\mathrm{C}_{3}$ and $\mathrm{C}_{2}$, respectively).

There is only a qualitative agreement with the experimental EPR-only data of Suzuki and Abe and the DFT calculated couplings for the $\mathrm{H}\left(\mathrm{C}_{3}\right)$ center. All couplings are predicted to be small in agreement with the narrow EPR resonance of Center No. 1. The agreement with the $\mathrm{C}_{2}$-centred radical is, however, extraordinarily good both with respect to the magnitude of the predicted couplings and the corresponding eigenvectors. These results 
therefore suggest that the Rochelle salt Center No. 1 is in fact a radical species formed by the net abstraction of an $\mathrm{H}$-atom from $\mathrm{C}_{2}$.

None of these calculations yielded results comparable with those expected for Center No. 3 in the Rochelle salt, as this resonance has been described by previous authors. It is, however, interesting to note that the width of the room temperature spectra is well accommodated by the $\beta-\mathrm{OH}$ elimination radical discussed in sections 5.4 and 6.3 above. This species is formed from the protonated one-electron reduced tartaric moiety as described above, making it probable that Center No. 3 in fact is this radical surviving from $120 \mathrm{~K}$ to room temperature where it decays slowly (Moulton and Moulton, 1961). All available literature data are consistent with this proposal. However, for a definitive answer to this issue, further studies must be made.

\section{Summary and Discussion}

The main new findings for the radiation induced free radical species in Rochelle salt may be summarized as follows: The one-electron reduction product observed after $\mathrm{X}$ irradiation at $10 \mathrm{~K}$ could be unambiguously located by ENDOR to the $\mathrm{C}_{4}$ position of the tartrate moiety from the coupling tensor data for the $\beta$-proton hyperfine interaction with $\mathrm{H}_{\beta} \mathrm{C}_{3}$. An additional hyperfine structure of about $21 \mathrm{MHz}$ was assigned to a sodium ion with a close contact to $\mathrm{O}_{7}$ in the crystal. No evidence for a $\mathrm{C}_{1}$-centred reduction product was found.

The two resonance lines R2 and A1 of Table 1 shown by EIE to belong to the same species have the characteristics of a radical formed by decarboxylation yielding a radical centred at $\mathrm{C}_{3}$. Two other decarboxylation products, both centred at $\mathrm{C}_{2}$, were attributed to other sets of hyperfine coupling tensors. A large $\alpha$-coupling A2 was tentatively ascribed to a fully decarboxylated radical, whereas two smaller $\alpha$-couplings $\mathrm{K} 1$ and $\mathrm{K} 2$ were ascribed to a 
partially decarboxylated product with the abstracted $\mathrm{CO}_{2}$ group trapped sufficiently close to the radical centre to carry some spin density which in turn is influenced by the fractional occupancy of potassium ions in the lattice.

Thermally induced free radical reactions followed by EPR in the temperature range 10 to $120 \mathrm{~K}$ support the conclusions from previous work that a water molecule or a hydroxyl ion is eliminated from the anion radical, thus forming a $\mathrm{C}_{3}$-centred radical. It is proposed that this radical is the same species as the classical Center No. 3 in irradiated Rochelle salt. Furthermore, the present DFT calculations indicate that Center No. 1 in irradiated Rochelle salt is the radical formed by net $\mathrm{H}$-abstraction from $\mathrm{C}_{2}$.

\subsection{Mechanisms}

Odd-electron primary reaction products formed by irradiation of carboxylic acids and their salts have previously been investigated by ESR and ENDOR at low temperature, 4-77 K (Iwasaki, 1972; Box, 1977). A general mechanism involving the formation and decomposition of one-electron oxidation and reduction species could be formulated on the basis of these experiments and has been developed particularly for carboxylic acids and their salts and for amino acids (Sagstuen et al., 2004). Based on the observations made in these previous works and the results obtained here a modified scheme for the formation of free radicals in hydroxy acids, e.g. tartaric acids and salts, is proposed, as shown below in Scheme 5.

Loss of an electron at the carboxylic group results, if the carboxyl group is protonated, in loss of a proton also. The resulting acyloxy radical $\mathrm{RCHOHCOO}$ was not observed in this work, and has been observed by EPR only in a few cases at very low temperatures (Iwasaki, 1972). 
The acyloxy radical decomposes upon warming or illumination, apparently by elimination of carbon dioxide forming a secondary radical, denoted by $\mathrm{RC} H O H$ in Scheme 5 , with $\mathrm{R}={ }^{-} \mathrm{OOC}-\mathrm{C}_{\beta} \mathrm{H}(\mathrm{OH})-$ for the species expected to form in the Rochelle salt. The R2 and A1 ENDOR lines observed after irradiation and measurement at $10 \mathrm{~K}$ is attributed to a species of this type. A pyramidal structure is also inferred from the calculations for this structure.

The decarboxylated radical may react with undamaged tartrate ions to form a secondary radical, ${ }^{-} \mathrm{OOC}_{4}-\mathrm{C}_{3} \mathrm{H}(\mathrm{OH})-\dot{\mathrm{C}}_{2}(\mathrm{OH})-\mathrm{C}_{1} \mathrm{OO}^{-}$. A species of this type is known from room temperature studies of irradiated ammonium tartrate (Brustolon et al., 1996) and Rochelle salt (Moulton and Moulton, 1961; Suzuki and Abe, 1968), and this structure is supported by DFT calculations in the present work. Due to the overlap with the signals from the species formed in the reduction pathway (see discussion below) the suggested reaction of the decarboxylated species could not be followed in the warm-up experiments shown in Figure 5.

Addition of an electron yields a reduced species that is stable at low temperature, but usually decays below room temperature. The reduction product is often protonated (Box, 1977), as indicated in the scheme. The decomposition reactions have been extensively studied (Box, 1977). For saturated carboxylic radicals, secondary radical products appear, including the $\mathrm{CO}_{2}^{-}$radical anion and acyl type radicals, RCO. Loss of ammonia and halogen, has been reported in substituted acids. In the present case other reactions involving water elimination from the the protonated and/or doubly protonated reduction product are possible as well, yielding in the first case a secondary radical of the type $\mathrm{RCHCOO}^{-}$with $\mathrm{R}={ }^{-} \mathrm{OOC}-$ $\mathrm{CH}(\mathrm{OH})-$. This species, ${ }^{-} \mathrm{OOC}-\mathrm{C}_{\beta} \mathrm{H}(\mathrm{OH})-\dot{\mathrm{C}}_{\alpha} \mathrm{H}-\mathrm{COO}^{-}$, discussed in sections 5.5 and 6.5, was observed experimentally in the warm-up studies as the four line EPR-spectrum in Fig. 5. If the spin of the one-electron reduction product can be stabilized at either end, water 
may also be lost at either end, giving rise to ${ }^{-} \mathrm{OOC}-\mathrm{C}_{\beta} \mathrm{H}(\mathrm{OH})-\dot{\mathrm{C}}_{\alpha} \mathrm{H}-\mathrm{COO}^{-}$radicals with different $\beta$-H hyperfine couplings due to different conformations. The appearance of the additional lines on the wings of the four-line spectrum during warm-up, seems to support the hypothesis that electron capture might occur at either end of the tartrate unit.

The proposed fragmentation reaction of the singly protonated reduction product may only be valid in hydroxy acid derivatives, while the alternative decomposition of the doubly protonated reduction product to an acyl radical, in principle applies more generally to carboxylic acids. The radical formed from the singly protonated reduction product is not stable at room temperature. In the diagram is indicated that the latter radical reacts with an undamaged tartrate unit to form the secondary radical known to be stable at room temperature in irradiated ammonium tartrate (Olsson et al., 1999; Olsson et al., 2000)

The excess electron of the one-electron reduced species might be expected to be trapped at both sides of the tartaric acid backbone. In the present work only one of the two possible reduction products is observed. Either the electron is transferred to the $\mathrm{C}_{4}$ position immediately upon electron capture, or the $\mathrm{C}_{1}$-centered anion has decayed into a secondary species already at $10 \mathrm{~K}$. 


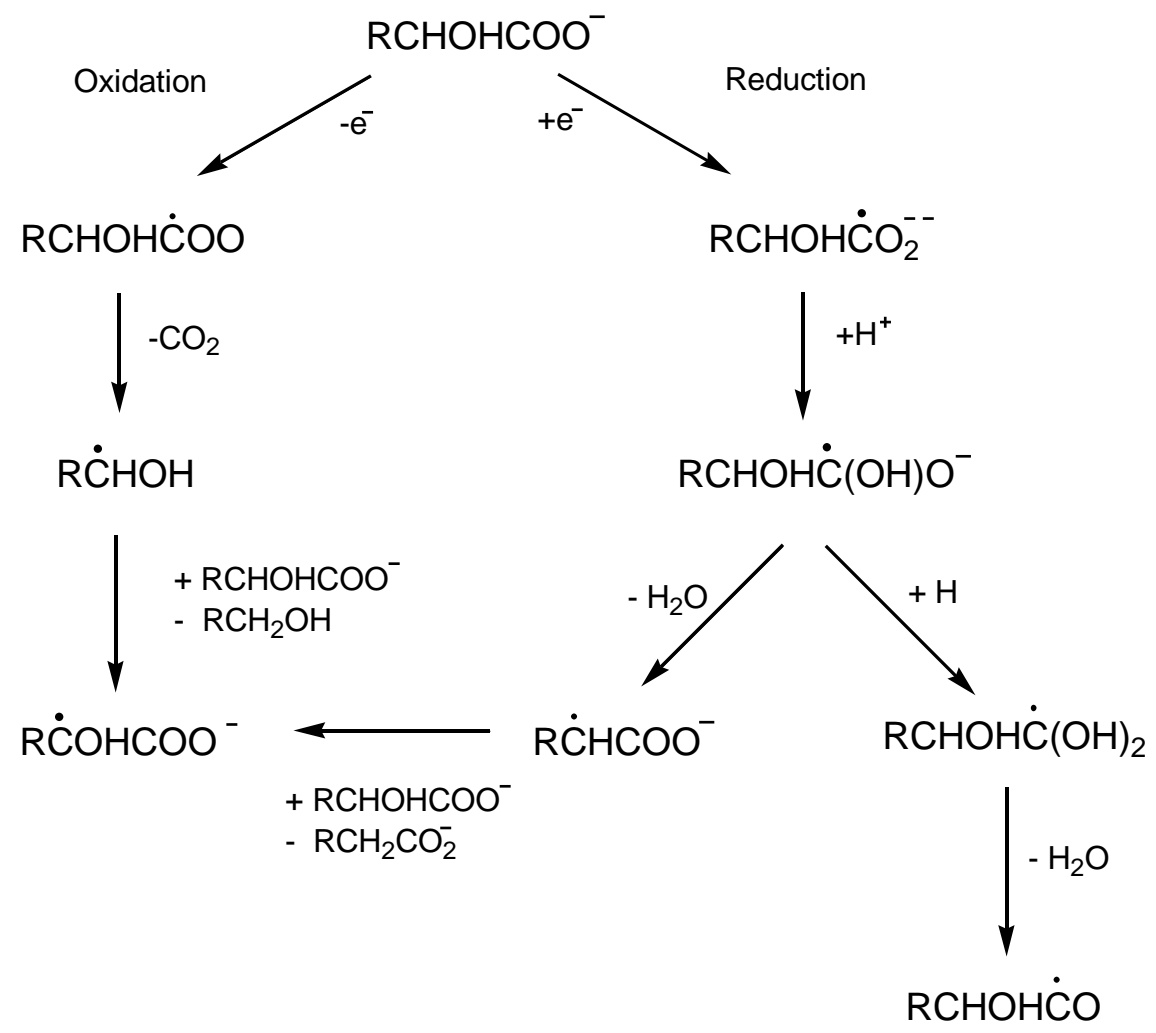

Scheme 5. Proposed reaction scheme for hydroxyl acids and salts

The radiation induced radicals of dl-tartaric acid that have been observed previously by EPR and ENDOR (Moulton and Cernansky, 1969; Moulton and Cernansky, 1970; Mulchinock and Hallett, 1972; Moulton and McDearmon, 1980) fit rather well into this scheme. As in the present work, the primary acyloxy radical was not observed even at $4.2 \mathrm{~K}$. A radical formed in a deuterated crystal assigned to the radical DOOC-CH(OD)- $\dot{\mathrm{C}} \mathrm{H}(\mathrm{OD})$ is similar to the species observed here to be formed in the oxidation pathway of the scheme.

The reduction product was an anion radical with the unpaired electron on the carboxylic group, exhibiting hyperfine coupling to a $\beta$-proton as in the present work. The suggested anion decay mechanism by loss of the $\mathrm{CO}_{2}{ }^{-}$anion was not considered in Scheme 5, however, since the spectrum of this radical anion could not be verified in the present work. Rather, a decay mechanism involving water elimination from the protonated anion shown in the scheme was suggested, in agreement with previous studies of the kinetics of anion decay and the growth of the secondary $\mathrm{RC}^{\circ} \mathrm{HCOO}^{-}$radical measured by pulse radiolysis in Rochelle 
salt. The same mechanism was proposed for the radical anion in di-K-tartrate in an EPR study (Samskog et al., 1979).

The ${ }^{-O O C}-\dot{\mathrm{C}} \mathrm{H}(\mathrm{OH})$ radical observed after room temperature irradiation of Rochelle salt (Suzuki and Abe, 1967; Suzuki and Abe, 1968) by cleavage of interior C-C bond was not considered in the scheme since no new mechanistic information was obtained in this study. 


\section{References}

Beevers, C. A., Hughes, W., 1941. Proc. R. Soc. London A 177, 251-259.

Bernhard, W. A., 1981. Solid-state radiation chemistry of DNA: the bases, in: J. T. Lett and K. I. Altman, Adv. Radiat. Biol., Academic Press, New York, 9, 199-280.

Bernhard, W. A., 1984. The use of alpha hyperfine coupling tensors as a measure of unpaired spin density and free radical geometry. J. Chem. Phys. 81, 5928-5936.

Box, H. C., 1977. Radiation Effects: ESR and ENDOR analysis. Academic Press, New York. Brustolon, M., Maniero, A. L., Jovine, S., Segre, U., 1996. ENDOR and ESEEM study of the radical obtained by $\gamma$ irradiation of a single crystal of ammonium tartrate. Res. Chem. Intermed. 22, 359-368.

Erling, P. A., Nelson, W. H., 2004. Dependence of alpha-proton Hyperfine Couplings on Free Radical Geometry. J. Phys. Chem. A 108, 7591 - 7595.

Frisch, M. J., Trucks, G. W., Schlegel, H. B., Scuseria, G. E., Robb, M. A., Cheeseman, J. R., Montgomeryjr., J. A., Vreven, T., Kudin, K. N., Burant, J. C., Millam, J. M., Iyengar, S. S., Tomasi, J., Barone, V., Mennucci, B., Cossi, M., Scalmani, G., Rega, N., Petersson, G. A., Nakatsuji, H., Hada, M., Ehara, M., Toyota, K., Fukuda, R., Hasegawa, J., Ishida, M., Nakajima, T., Honda, Y., Kitao, O., Nakai, H., Klene, M., Li, X., Knox, J. E., Hratchian, H. P., Cross, J. B., Adamo, C., Jaramillo, J., Gomperts, R., Stratmann, R. E., Yazyev, O., Austin, A. J., Cammi, R., Pomelli, C., Ochterski, J. W., Ayala, P. Y., Morokuma, K., Voth, G. A., Salvador, P., Dannenberg, J. J., Zakrzewski, V. G., Dapprich, S., Daniels, A. D., Strain, M. C., Farkas, O., Malick, D. K., Rabuck, A. D., Raghavachari, K., Foresman, J. B., Ortiz, J. V., Cui, Q., Baboul, A. G., Clifford, S., Cioslowski, J., Stefanov, B. B., Liu, G., Liashenko, A., Piskorz, P., Komaromi, I., Martin, R. L., Fox, D. J., Keith, T., Al-Laham, M. A., Peng, C. Y., Nanayakkara, A., Challacombe, M., Gill, P. M. W., Johnson, B., Chen, W., Wong, M. W., Gonzalez, C., Pople, J. A., 2003. Gaussian 03. Pittsburgh PA, Gaussian Inc.

Görbitz, C. H., Sagstuen, E., 2008. Potassium sodium (2R,3R)-tartrate tetrahydrate: the paraelectric phase of Rochelle salt at 105 K. Acta. Crystallogr. E 64, m507-m508. Iwasaki, M., 1972. E.S.R. Study of Irradiated Organic Crystals, in: C. A. McDowell, Magnetic Resonance, Butterworths University Park Press, London, 4, 317-347.

Kolbun, N., Leveque, P., Abboud, F., Bol, A., Vynckier, S., Gallez, B., 2010. Experimental determination of the radial dose distribution in high gradient regions around Ir-192 
wires: Comparison of electron paramagnetic resonance imaging, films, and Monte Carlo simulations. Med. Phys. 37, 5448-5455.

Lipfert, J., Llano, J., Eriksson, L. A., 2004. Radiation-Induced Damage in Serine Phosphates - Insights into a Mechanism for Direct DNA Strand Breakage. J. Phys. Chem. B 108, 8036-8042.

McConnell, H. M., Chesnut, D. B., 1958. Theory of isotropic hyperfine interactions in $\pi$ electron radicals. J. Chem. Phys. 28, 107-117.

Moulton, G. C., Cernansky, B., 1970. ESR studies of deuterated dl-tartaric acid X-irradiated at 195 K. J. Chem. Phys. 53, 3022-3025.

Moulton, G. C., Cernansky, M. P., 1969. Electron spin resonance of X-irradiated single crystals of DL-tartaric acid at 77 K. J. Chem. Phys. 51, 2283-2284.

Moulton, G. C., McDearmon, G., 1980. Primary radiation products of dl-tartaric acid: ESR and ENDOR at 4.2 K. J. Chem. Phys. 72, 1665-1668.

Moulton, G. C., Moulton, W. G., 1961. Paramagnetic resonance of X-irradiated single crystals of Rochelle salt. J. Chem. Phys. 35, 208-212.

Mulchinock, J. K., Hallett, F. R., 1972. ESR studies of $\gamma$-irradiated single crystal of D-tartaric acid. Can. J. Chem. 50, 3706-3713.

Muto, H., 1991. Trapped anions in organic systems, in: A. Lund and M. Shiotano, Radical Ionic Systems. Properties in condensed phases., Kluwer Academic Publishers, Dordrecht, 337-360.

Nelson, W. H., 1980. Estimation of errors in eigenvectors and eigenvalues from magnetic resonance results using linear data-fitting techniques. J. Magn. Reson. 38, 71-78.

Nelson, W. H., Nave, C. R., 1981. ESR and ENDOR studies of radicals produced in hydroxyproline single crystals by x-irradiation at low temperature. J. Chem. Phys. 74, 2710-2716.

Øhman, K. T., Sagstuen, E., 2008. Free Radical Conformations and Conversions in XIrradiated Single Crystals of L-Cysteic Acid by Electron Magnetic Resonance and Density Functional Theory Studies. J. Phys. Chem. A 112, 4284-4293.

Øhman, K. T., Sanderud, A., Hole, E. O., Sagstuen, E., 2006. Single Crystals of L-O-Serine Phosphate X-Irradiated at Low Temperatures: EPR, ENDOR, EIE, and DFT studies. J. Phys. Chem. A 110, 9585-9596.

Olsson, S., Bagherian, S., Lund, E., Carlsson, G. A., Lund, A., 1999. Ammonium tartrate as an ESR dosimeter material. Appl. Radiat. Isot. 50, 955-965. 
Olsson, S. K., Lund, E., Lund, A., 2000. Development of ammonium tartrate as an ESR dosimeter material for clinical purposes. Appl. Radiat. Isot. 52, 1235-1241.

Sagstuen, E., Hole, E. O., Haugedal, S. R., Lund, A., Eid, O. I., Erickson, R., 1997. EPR and ENDOR analysis of $\mathrm{x}$-irradiated L-alanine and $\mathrm{NaHC}_{2} \mathrm{O}_{4} \cdot \mathrm{H}_{2} \mathrm{O}$. Simulation of microwave power dependence of satellite lines. Nukleonika 42, 353-372.

Sagstuen, E., Lund, A., Itagaki, Y., Maruani, J., 2000. Weakly Coupled Proton Interactions in the Malonic Acid Radical: Single Crystal ENDOR Analysis and EPR Simulation at Microwave Saturation. J. Phys. Chem. A 104, 6362-6371.

Sagstuen, E., Sanderud, A., Hole, E. O., 2004. The Solid State Radiation Chemistry of Simple Amino Acids, Revisited. Radiat. Res. 162, 112 - 119.

Samskog, P.-O., Lund, A., 1982. ESR single crystal study of OH radicals in X-irradiated salts of tartaric acid at $26 \mathrm{~K}$. Chem. Phys. Lett. 86, 518-521.

Samskog, P.-O., Lund, A., Nilsson, G., Symons, M. C. R., 1979. Primary reactions in crystalline salts of tartaric acids studied by EPR spectroscopy. Chem. Phys. Lett. 66, 199-202.

Samskog, P.-O., Nilsson, G., Lund, A., 1978. Primary reactions in crystalline Rochelle salt studied by pulse radiolysis and EPR spectroscopy. The decarboxylation of the acyloxy radical ion. J. Chem. Phys. 68, 4986-4991.

Schonland, D. S., 1959. On the Determination of the Principal g-values in Electron Spin Resonance. Proc. Phys. Soc 73, 788-792.

Solans, X., Gonzalez-Silgo, C., Ruiz-Perez, C., 1997. A structural study on the Rochelle salt. J. Solid State Chem. 131, 350-357.

Suzuki, I., 1974. Negative ENDOR study of an X-ray irradiated crystal of Rochelle salt. J. Phys. Soc. Jpn. 37, 1379-1384.

Suzuki, I., Abe, R., 1967. Electron spin resonance of gamma-irradiated Rochelle salt single crystal. I. Analysis of center No. 2. J. Phys. Soc. Jpn. 23, 1049-1056.

Suzuki, I., Abe, R., 1968. Electron spin resonance of gamma-irradiated Rochelle salt single crystal. II. Analysis of center No. 1. J. Phys. Soc. Jpn. 25, 783-788.

Toriyama, K., Iwasaki, M., 1976. $\mathrm{CH}_{3}{ }^{\cdots \cdot 13} \mathrm{CO}_{2}$ pairs in irradiated single crystals of $\mathrm{CH}_{3}{ }^{13} \mathrm{CO}_{2} .2 \mathrm{D}_{2} \mathrm{O}$. J. Chem. Phys. 65, 2883-2886.

Van Treek, E., Windsch, W., 1977. Influence of energetic excitation on the structure and location of the Radical II in X-irradiated Rochelle salt studied by ENDOR. J. Magn. Reson. 25, 15-23. 
Vrielinck, H., De Cooman, H., Tarpan, M. A., Sagstuen, E., Waroquier, M., Callens, F., 2008. Schonland ambiguity in the electron nuclear double resonance analysis of hyperfine interactions: Principles and practice. J. Magn. Reson. 195, 196-205. 
Table 1: ENDOR determined proton hyperfine coupling tensors $(\mathrm{MHz})$ from partially deuterated crystals of Rochelle salt X-irradiated and measured at $10 \mathrm{~K}$.

\begin{tabular}{|c|c|c|c|c|c|c|}
\hline \multirow{2}{*}{ Radical } & \multirow{2}{*}{ Tensor } & \multirow{2}{*}{$\begin{array}{l}\text { Isotropic } \\
\text { value }\end{array}$} & \multirow{2}{*}{$\begin{array}{c}\text { Principal } \\
\text { values }\end{array}$} & \multicolumn{3}{|c|}{ Eigenvectors } \\
\hline & & & & $\langle\mathrm{a}\rangle$ & $\langle\mathrm{b}\rangle$ & $\langle c\rangle$ \\
\hline $\begin{array}{l}\text { Protonated } \\
\text { anion } \\
\left(\mathrm{C}_{4}\right)\end{array}$ & $\mathrm{R} 1$ & $57.68(1)$ & $\begin{array}{l}65.30(2) \\
54.98(1) \\
52.75(1)\end{array}$ & $\begin{array}{l}0.0432(10) \\
0.6833(1) \\
0.7289(8)\end{array}$ & $\begin{array}{c}0.9847(12) \\
-0.1525(8) \\
0.0846(11)\end{array}$ & $\begin{array}{r}0.1690(11) \\
0.7141(12) \\
-0.6794(11)\end{array}$ \\
\hline Decarboxy- & $\mathrm{R} 2$ & $27.80(1)$ & $\begin{array}{l}37.91(2) \\
24.06(2) \\
21.44(2)\end{array}$ & $\begin{array}{r}0.5262(8) \\
-0.6515(9) \\
-0.5464(8)\end{array}$ & $\begin{array}{r}-0.6033(29) \\
0.1668(42) \\
-0.7799(17)\end{array}$ & $\begin{array}{r}0.5993(37) \\
0.7400(12) \\
-0.3053(38)\end{array}$ \\
\hline $\begin{array}{l}\text { lated } \\
\left(\mathrm{C}_{3}\right)\end{array}$ & A1 & $-48.80(3)$ & $\begin{array}{l}-81.71(7) \\
-47.70(4) \\
-16.99(4)\end{array}$ & $\begin{array}{l}0.8898(3) \\
0.2067(7) \\
0.4068(7)\end{array}$ & $\begin{array}{c}-0.1104(5) \\
-0.7675(8) \\
0.6315(10)\end{array}$ & $\begin{array}{r}0.4427(6) \\
-0.6068(9) \\
-0.6601(7)\end{array}$ \\
\hline $\begin{array}{c}\text { Decarboxy- } \\
\text { lated } \\
\left(\mathrm{C}_{2}\right)\end{array}$ & A2 & $-40.35(2)$ & $\begin{array}{r}-73.61(4) \\
-37.60(4) \\
-9.84(5)\end{array}$ & $\begin{array}{l}0.0200(8) \\
0.3994(3) \\
0.9166(2)\end{array}$ & $\begin{array}{c}0.6404(13) \\
0.6989(7) \\
-0.3185(5)\end{array}$ & $\begin{array}{c}-0.7678(6) \\
0.5934(11) \\
-0.2417(9)\end{array}$ \\
\hline $\begin{array}{c}\text { Decarboxy- } \\
\text { lated } \\
\left(\mathrm{C}_{2}\right)\end{array}$ & K2 & $-25.06(1)$ & $\begin{array}{l}-34.21(2) \\
-26.10(2) \\
-14.88(2)\end{array}$ & $\begin{array}{l}-0.4302(8) \\
-0.2702(9) \\
-0.8613(10)\end{array}$ & $\begin{array}{r}0.7573(10) \\
-0.6273(13) \\
-0.1815(14)\end{array}$ & $\begin{array}{c}0.4913(5) \\
0.7304(13) \\
-0.4745(11)\end{array}$ \\
\hline Partially & K1 & $-24.09(1)$ & $\begin{array}{l}-33.38(2) \\
-25.14(2) \\
-13.76(2)\end{array}$ & $\begin{array}{l}-0.4231(8) \\
-0.2608(9) \\
-0.8677(10)\end{array}$ & $\begin{array}{r}-0.7576(10) \\
0.6271(13) \\
0.1810(14)\end{array}$ & $\begin{array}{c}0.4969(5) \\
0.7340(13) \\
-0.4630(12)\end{array}$ \\
\hline $\begin{array}{l}\text { Crystallograp } \\
\mathrm{C}_{3}-\mathrm{O}_{6} \\
\mathrm{C}_{2}-\mathrm{O}_{5} \\
\mathrm{C}_{3}-\mathrm{C} 4 \\
\mathrm{C}_{3}-\mathrm{H}_{3} \\
\mathrm{C}_{2}-\mathrm{H}_{2} \\
\mathrm{C}_{1}-\mathrm{C}_{2} \\
\mathrm{C}_{2}-\mathrm{H}_{3} \\
\mathrm{C}_{3}-\mathrm{H}_{2} \\
\mathrm{C}_{4}-\mathrm{H}_{3} \\
\mathrm{C}_{1}-\mathrm{H}_{2}\end{array}$ & ic directi & & & $\begin{array}{r}-0.9873 \\
-0.3347 \\
-0.2218 \\
0.4786 \\
0.9988 \\
0.2329 \\
-0.0666 \\
-0.7773 \\
-0.0696 \\
0.6896\end{array}$ & $\begin{array}{r}0.1466 \\
-0.8394 \\
0.8031 \\
0.7338 \\
0.0314 \\
-0.7934 \\
0.4240 \\
0.0517 \\
-0.9809 \\
-0.5761\end{array}$ & $\begin{array}{r}0.0606 \\
0.4281 \\
0.5530 \\
-0.4822 \\
-0.0368 \\
-0.5624 \\
-0.9032 \\
-0.6270 \\
-0.1818 \\
-0.4388\end{array}$ \\
\hline
\end{tabular}

\footnotetext{
${ }^{a}$ Numbers in parentheses are the standard deviation in the least significant digit(s) given.
} 
Table 2: DFT-calculated hyperfine coupling tensors (in $\mathrm{MHz}$ ) for the O4-protonated oneelectron reduced radical in Rochelle salt. The experimental data not provided here are given in Table 1. $\Delta \varphi$ is the angle of deviation for the indicated eigenvector with that of the corresponding experimental eigenvector.

\begin{tabular}{|c|c|c|c|c|c|}
\hline Radical & $\operatorname{Exp} / D F T$ & $\begin{array}{l}\text { Coupling } \\
\text { Nucleus }\end{array}$ & $\begin{array}{c}\text { Isotropic } \\
\text { Value }\end{array}$ & $\begin{array}{c}\text { Anisotropic } \\
\text { Princ. } \\
\text { Values }\end{array}$ & $\Delta \varphi\left(^{\circ}\right)$ \\
\hline & Exp & ${ }^{13} \mathrm{C}$ & 229 & $\begin{array}{r}130 \\
-58 \\
-72\end{array}$ & \\
\hline$-\mathrm{OOC}_{1}-\mathrm{C}_{2} \mathrm{H}(\mathrm{OH})-$ & DFT & ${ }^{13} \mathrm{C}$ & 291 & $\begin{array}{r}99 \\
-49 \\
-50\end{array}$ & 5 \\
\hline $\mathrm{C}_{3} \mathrm{H}_{\beta}(\mathrm{OH})-\dot{\mathrm{C}}_{4} \mathrm{OOH}^{-}$ & DFT & $\mathrm{H}_{\beta}\left(\mathrm{C}_{3}\right)$ & 43.2 & $\begin{array}{r}7.9 \\
-3.2 \\
-4.9\end{array}$ & 3.5 \\
\hline & DFT & $\mathrm{H}\left(\mathrm{O}_{4}\right)$ & 83 & & \\
\hline
\end{tabular}


Table 3: DFT-calculated hyperfine coupling tensors (in $\mathrm{MHz}$ ) for $\mathrm{C}_{3}$-decarboxylated oneelectron oxidation product in Rochelle salt. The experimental data not provided here are given in Table 1. $\Delta \varphi$ is the angle of deviation for the indicated eigenvector with that of the corresponding experimental eigenvector.

\begin{tabular}{|c|c|c|c|c|c|}
\hline Radical & $\operatorname{Exp} / D F T$ & $\begin{array}{l}\text { Coupling } \\
\text { Nucleus }\end{array}$ & $\begin{array}{c}\text { Isotropic } \\
\text { Value }\end{array}$ & $\begin{array}{c}\text { Anisotropic } \\
\text { Princ. } \\
\text { Values }\end{array}$ & $\Delta \varphi\left(^{\circ}\right)$ \\
\hline & DFT & ${ }^{13} \mathrm{C}$ & 202 & $\begin{array}{r}118 \\
-58 \\
-60\end{array}$ & \\
\hline$-\mathrm{OOC}_{1}-\mathrm{C}_{2} \mathrm{H}_{\beta}(\mathrm{OH})-$ & DFT & $\mathrm{H}_{\alpha}\left(\mathrm{C}_{3}\right)$ & -10.3 & $\begin{array}{r}-29.0 \\
-4.2 \\
33.2\end{array}$ & $\begin{array}{l}26 \\
18\end{array}$ \\
\hline$\dot{C}_{\alpha} \mathrm{H}_{\alpha}(\mathrm{OH})$ & DFT & $\mathrm{H}_{\beta}\left(\mathrm{C}_{2}\right)$ & 33.8 & $\begin{array}{l}10.6 \\
-4.5 \\
-6.1\end{array}$ & 35 \\
\hline & DFT & $\mathrm{H}\left(\mathrm{O}_{6}\right)$ & -11.1 & & \\
\hline
\end{tabular}


Table 4: DFT-calculated hyperfine coupling tensors (in $\mathrm{MHz}$ ) for $\mathrm{C}_{2}$ centred partially decarboxylated one-electron oxidated tartrate moiety in Rochelle salt. The experimental data are given in Table 1 (the $\mathrm{K} 1$ tensor). $\Delta \varphi$ is the angle of deviation for the indicated eigenvector with that of the corresponding experimental eigenvector.

\begin{tabular}{cccccc}
\hline Radical & Exp/DFT & $\begin{array}{c}\text { Coupling } \\
\text { Nucleus }\end{array}$ & $\begin{array}{c}\text { Isotropic } \\
\text { Value }\end{array}$ & $\begin{array}{c}\text { Anisotropic } \\
\text { Princ. Values }\end{array}$ & \multicolumn{1}{c}{$\boldsymbol{\Delta \varphi}\left({ }^{\circ}\right)$} \\
\hline & & & & -11.47 & \\
& & & & -4.76 & 17 \\
$\mathrm{OOC}_{1} \cdots \dot{C}_{2} \mathrm{H}_{\alpha}(\mathrm{OH})-$ & & $\mathrm{H}_{\alpha}\left(\mathrm{C}_{2}\right)$ & -10.3 & 16.23 & 26 \\
& & & & & \\
$\mathrm{C}_{3} \mathrm{H}_{\beta}(\mathrm{OH})-\mathrm{C}_{4} \mathrm{OO}^{-}$ & & & & 4.96 & $-^{\mathrm{a}}$ \\
& \multirow{2}{*}{$\mathrm{DFT}$} & $\mathrm{H}_{\beta}\left(\mathrm{C}_{3}\right)$ & -5.4 & 0.87 & \\
& & & & -5.83 & \\
\hline
\end{tabular}

${ }^{\mathrm{a}}$ This coupling was not observed in the experiments. 
Table 5: DFT-calculated hyperfine coupling tensors (in $\mathrm{MHz}$ ) for $\mathrm{C}_{2}$-decarboxylated oneelectron oxidated tartrate moiety in Rochelle salt. The experimental data not provided here are given in Table 1. $\Delta \varphi$ is the angle of deviation for the indicated eigenvector with that of the corresponding experimental eigenvector.

\begin{tabular}{|c|c|c|c|c|c|}
\hline Radical & $\operatorname{Exp} / D F T$ & $\begin{array}{c}\text { Coupling } \\
\text { Nucleus } \\
\end{array}$ & $\begin{array}{c}\text { Isotropic } \\
\text { Value }\end{array}$ & $\begin{array}{c}\text { Anisotropic } \\
\text { Princ. Values } \\
\end{array}$ & $\Delta \varphi\left(^{\circ}\right)$ \\
\hline & & & & 127 & \\
\hline & DFT & ${ }^{13} \mathrm{C}$ & 215 & -63 & \\
\hline & & & & -64 & \\
\hline & & & & -31.1 & \\
\hline & DFT & $\mathrm{H}_{\alpha}\left(\mathrm{C}_{2}\right)$ & -36.3 & -4.8 & 27 \\
\hline$\dot{C}_{2} \mathrm{H}_{\alpha}(\mathrm{OH})-$ & & & & 33.9 & 20 \\
\hline \multirow[t]{4}{*}{$\mathrm{C}_{3} \mathrm{H}_{\beta}(\mathrm{OH})-\mathrm{C}_{4} \mathrm{OO}^{-}$} & & & & 11.1 & $-{ }^{\mathrm{a}}$ \\
\hline & DFT & $\mathrm{H}_{\beta}\left(\mathrm{C}_{3}\right)$ & 39.3 & -4.8 & \\
\hline & & & & -6.3 & \\
\hline & DFT & $\mathrm{H}\left(\mathrm{O}_{5}\right)$ & 14.1 & & \\
\hline
\end{tabular}

${ }^{a}$ This coupling was not observed experimentally. This eigenvector, however, deviates $19^{\circ}$ from the crystallographic $\mathrm{C} 2 \cdots \mathrm{H} 3$ direction. 
Table 6: DFT-calculated hyperfine coupling tensors (in $\mathrm{MHz}$ ) for radical formed from the $\mathrm{O}_{4^{-}}$ protonated one-electron reduced tartrate moiety by $\beta-\mathrm{OH}$ elimination, ${ }^{-} \mathrm{OOC}_{1}-\mathrm{C}_{\beta} \mathrm{H}(\mathrm{OH})$ $\dot{\mathrm{C}}_{\alpha} \mathrm{H}-\mathrm{C}_{4} \mathrm{OO}^{-}$in Rochelle salt. $\Delta \varphi$ is the angle of deviation for the indicated eigenvector with that of the corresponding experimental eigenvector. The experimental data are taken from ref. (Samskog et al., 1979). ${ }^{\mathrm{a}}$

\begin{tabular}{|c|c|c|c|c|c|}
\hline Radical & $\operatorname{Exp} / D F T$ & $\begin{array}{c}\text { Coupling } \\
\text { Nucleus } \\
\end{array}$ & $\begin{array}{c}\text { Isotropic } \\
\text { Value }\end{array}$ & $\begin{array}{c}\text { Anisotropic } \\
\text { Princ. Values } \\
\end{array}$ & $\Delta \varphi\left(^{\circ}\right)$ \\
\hline \multirow{6}{*}{$\begin{array}{c}\stackrel{\mathrm{OO}}{1} \mathrm{C}-^{\mathrm{C}-} \\
\mathrm{C}_{\beta} \mathrm{H}(\mathrm{OH})-\dot{\mathrm{C}}_{\alpha} \mathrm{H}-\end{array}$} & Exp & ${ }^{13} \mathrm{C}$ & 167 & $\begin{array}{l}104 \\
-21 \\
-83\end{array}$ & \\
\hline & DFT & ${ }^{13} \mathrm{C}$ & 121.6 & $\begin{array}{l}132.9 \\
-66.3 \\
-66.6\end{array}$ & 22 \\
\hline & Exp & $\mathrm{H}_{\beta}\left(\mathrm{C}_{2}\right)$ & 29.8 & $\begin{array}{l}10.2 \\
-2.1 \\
-7.4\end{array}$ & \\
\hline & DFT & $\mathrm{H}_{\beta}\left(\mathrm{C}_{2}\right)$ & 60.8 & $\begin{array}{r}8.9 \\
-3.1 \\
-5.9\end{array}$ & 19 \\
\hline & Exp & $\mathrm{H}_{\alpha}\left(\mathrm{C}_{3}\right)$ & -52.3 & $\begin{array}{r}-26.1 \\
1.9 \\
24.3\end{array}$ & \\
\hline & DFT & $\mathrm{H}_{\alpha}\left(\mathrm{C}_{3}\right)$ & -54.9 & $\begin{array}{r}-33.7 \\
-3.5 \\
37.2\end{array}$ & $\begin{array}{l}17 \\
13\end{array}$ \\
\hline
\end{tabular}

${ }^{\text {a }}$ For both the ${ }^{13} \mathrm{C}$ and the $\mathrm{H}_{\alpha}\left(\mathrm{C}_{3}\right)$ couplings, a $\mathrm{c} \rightarrow$-c sign transformation of the experimentally obtained eigenvectors have been made to optimize agreement with the calculated data. For the $\beta$-coupling, the $2^{\text {nd }}$ Schonland solution was chosen for symmetry reasons.(Schonland, 1959) It should be noted that the experimental data reported here are EPR only. 
Table 7: DFT-calculated hyperfine coupling tensors (in $\mathrm{MHz}$ ) for radicals formed by $\mathrm{H}$ abstraction from $\mathrm{C}_{3},{ }^{-} \mathrm{OO}_{1} \mathrm{C}-\mathrm{C}_{\beta} \mathrm{H}(\mathrm{OH})-\dot{\mathrm{C}}_{3}(\mathrm{OH})-\mathrm{C}_{4} \mathrm{OO}^{-}$and from $\mathrm{C} 2,{ }^{-} \mathrm{OO}_{1} \mathrm{C}-\dot{\mathrm{C}}_{2}(\mathrm{OH})$ $\mathrm{C}_{\beta} \mathrm{H}(\mathrm{OH})-\mathrm{C}_{4} \mathrm{OO}^{-}$in Rochelle salt $\mathrm{X}$-irradiated at room temperature. $\Delta \varphi$ is the angle of deviation for the indicated eigenvector with that of the corresponding experimental eigenvector. The experimental data are taken from ref. (Suzuki and Abe, 1968).

\begin{tabular}{|c|c|c|c|c|c|}
\hline Radical & $\operatorname{Exp} / D F T$ & $\begin{array}{l}\text { Coupling } \\
\text { Nucleus }\end{array}$ & $\begin{array}{c}\text { Isotropic } \\
\text { Value }\end{array}$ & $\begin{array}{c}\text { Anisotropic } \\
\text { Princ. Values }\end{array}$ & $\Delta \varphi\left(^{\circ}\right)$ \\
\hline \multirow{13}{*}{$\begin{array}{l}-\mathrm{OO}_{1} \mathrm{C}-\mathrm{C}_{\beta} \mathrm{H}(\mathrm{OH})- \\
\dot{\mathrm{C}}_{3}(\mathrm{OH})-\mathrm{C}_{4} \mathrm{OO}^{-}\end{array}$} & & & & 10.9 & \multirow{8}{*}{26} \\
\hline & Exp & $\mathrm{H}_{\beta}\left(\mathrm{C}_{2}\right)$ & 4.2 & -4.2 & \\
\hline & & & & -6.7 & \\
\hline & \multirow{5}{*}{ DFT } & \multirow{5}{*}{$\mathrm{H}_{\beta}\left(\mathrm{C}_{2}\right)$} & \multirow{5}{*}{2.4} & 9.3 & \\
\hline & & & & -3.5 & \\
\hline & & & & -5.8 & \\
\hline & & & & & \\
\hline & & & & $(+) 15.1^{\mathrm{a}}$ & \\
\hline & \multirow[t]{2}{*}{ Exp } & \multirow[t]{2}{*}{$\mathrm{H}_{\beta}(\mathrm{OH})$} & \multirow[t]{2}{*}{$(-) 3.9$} & $(-) 5.6$ & \multirow{5}{*}{55} \\
\hline & & & & $(-) 9.5$ & \\
\hline & \multirow{3}{*}{ DFT } & \multirow{3}{*}{$\mathrm{H}_{\beta}(\mathrm{OH})$} & \multirow{3}{*}{15.6} & 17.1 & \\
\hline & & & & -6.0 & \\
\hline & & & & -11.1 & \\
\hline \multirow{6}{*}{$\begin{array}{l}{ }^{-} \mathrm{OO}_{1} \mathrm{C}-\dot{\mathrm{C}}_{2}(\mathrm{OH})- \\
\mathrm{C}_{3} \mathrm{H}(\mathrm{OH})-\mathrm{C}_{4} \mathrm{OO}^{-}\end{array}$} & \multirow{3}{*}{ DFT } & \multirow{3}{*}{$\mathrm{H}_{\beta}\left(\mathrm{C}_{3}\right)$} & \multirow{3}{*}{3.7} & 9.3 & \multirow[t]{3}{*}{13} \\
\hline & & & & -3.4 & \\
\hline & & & & -5.9 & \\
\hline & \multirow{3}{*}{ DFT } & \multirow{3}{*}{$\mathrm{H}_{\beta}(\mathrm{OH})$} & \multirow{3}{*}{-8.5} & 19.9 & \multirow[t]{3}{*}{11} \\
\hline & & & & -8.7 & \\
\hline & & & & -11.2 & \\
\hline
\end{tabular}

\footnotetext{
${ }^{\mathrm{a}}$ The sign reversals in parentheses are included by the present authors to allow for a positive maximum dipolar coupling
} 
Schemes:

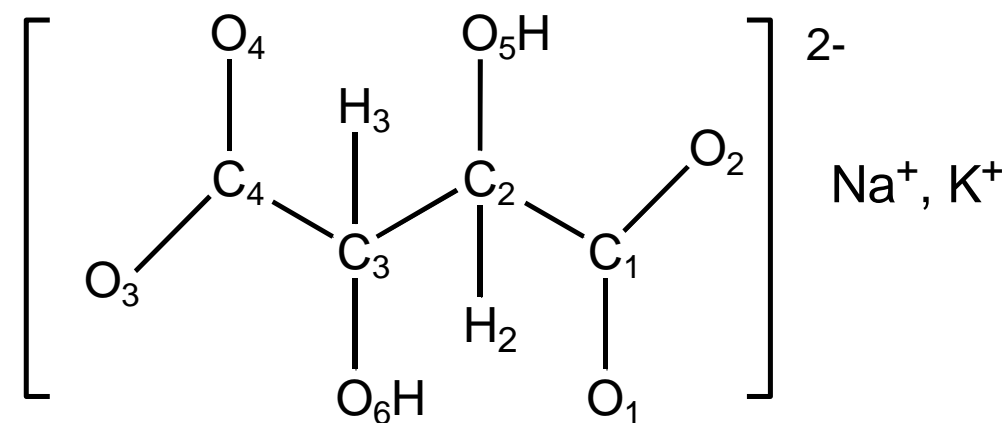

Scheme 1. The Rochelle salt

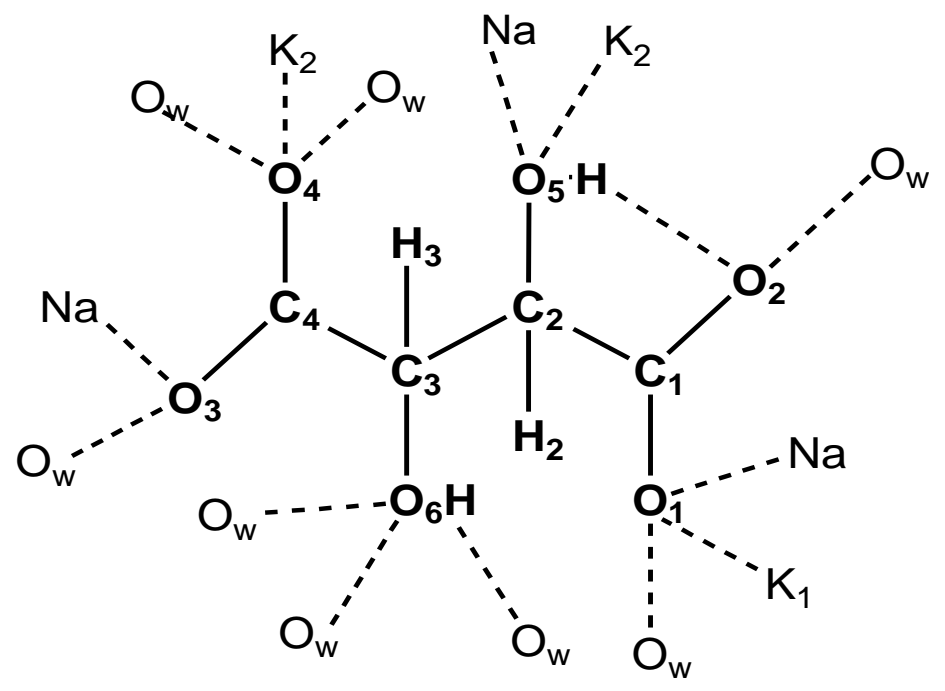

Scheme 2. Rochelle salt carboxyl group coordination

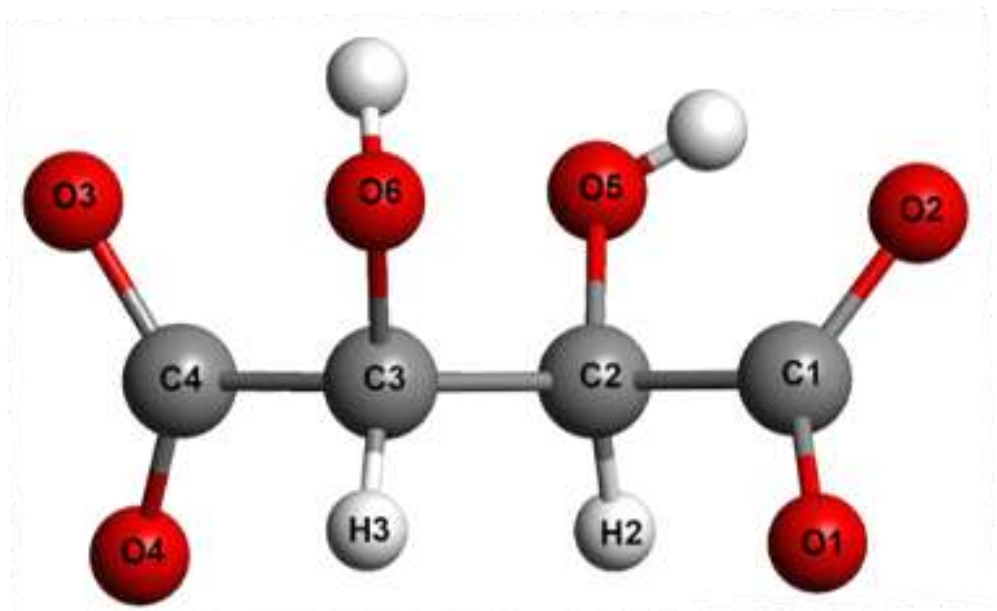

Scheme 3. Backbone configuration of the Rochelle salt 
(a)

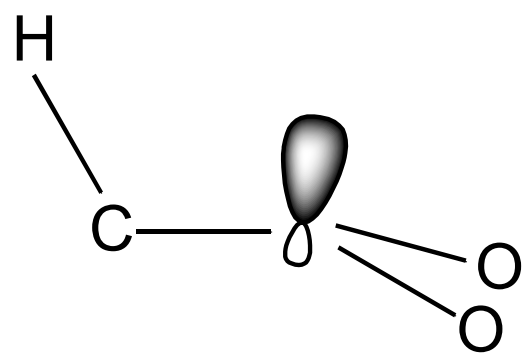

(b)

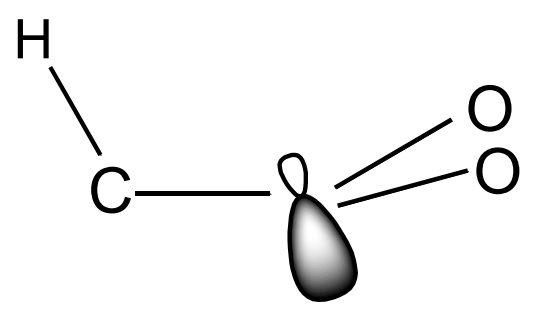

Scheme 4: $(a)$ cis and (b) trans configurations of the lone electron orbital with respect to the $C$ - $H^{\beta}$-bond

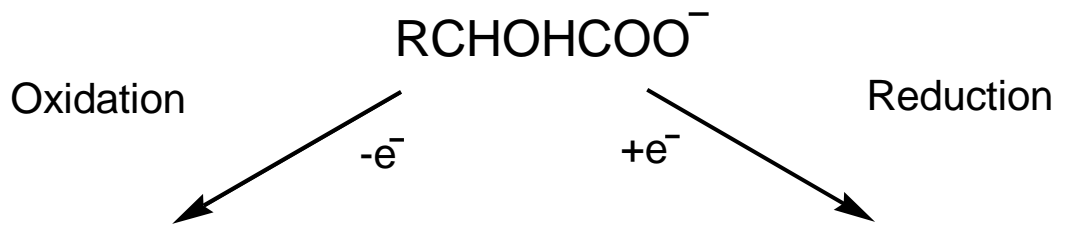

$\mathrm{RCHOHC்OO}$<smiles>[Y]C(=O)O</smiles>

$\mathrm{RC} \mathrm{HOH}$

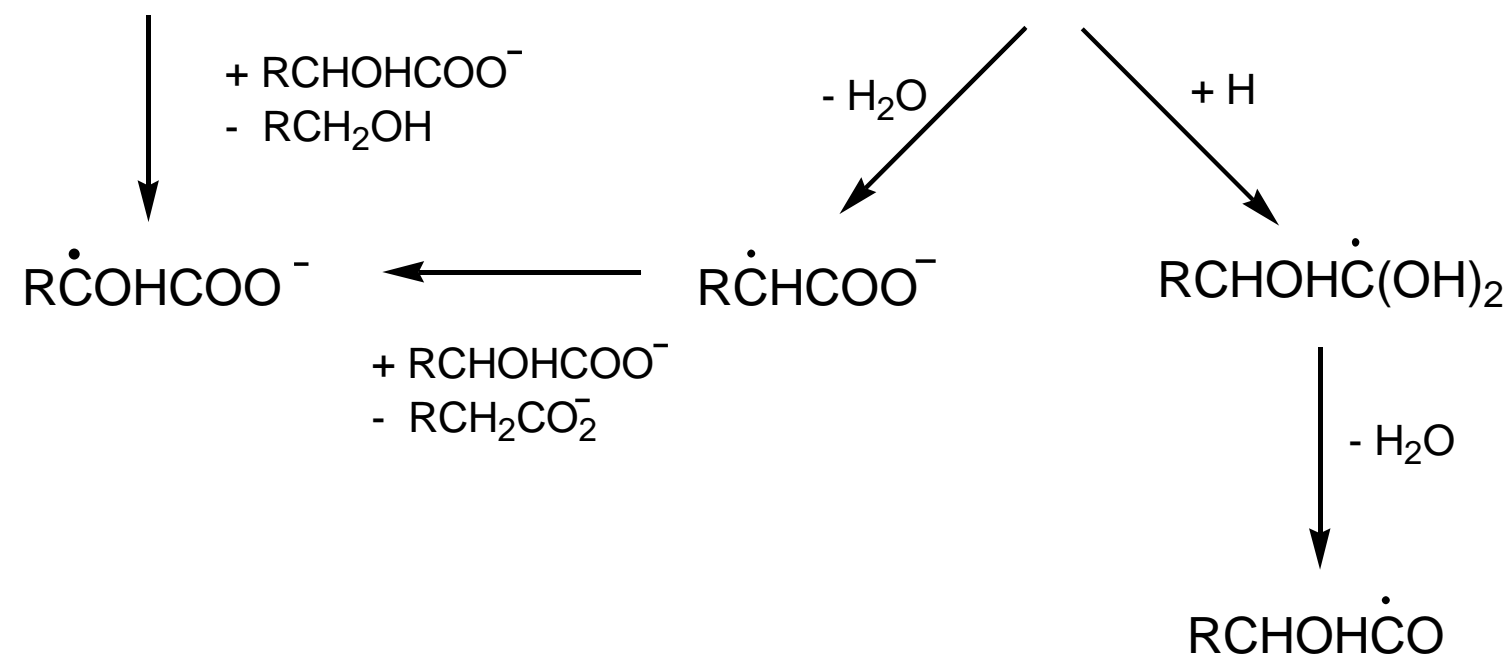

Scheme 5. Proposed reaction scheme for hydroxyl acids and salts 


\section{Figure Captions}

Figure 1: X-band first derivative EPR spectra from partially deuterated crystals of Rochelle salt irradiated and measured at $10 \mathrm{~K}$. The magnetic field was directed along the crystallographic axes as indicated. The magnetic field position for the free spin g-value, 2.00232 , is indicated on the field axis.

Figure 2: First derivative ENDOR spectra from partially deuterated crystals of Rochelle salt $\mathrm{X}$-irradiated and measured at $10 \mathrm{~K}$. The spectra were measured with the magnetic field directed along the crystallographic a-axis (Figure 1, top) with the magnetic field set at the positions (from top) $348.2 \mathrm{mT}, 347.3 \mathrm{mT}$ and $346.2 \mathrm{mT}$.

Figure 3: ENDOR line variations upon rotation about the crystallographic c-axis of a partially deuterated crystal of Rochelle salt X-irradiated and measured at $10 \mathrm{~K}$. The magnetic field was locked at a central resonance line of the EPR spectra (see Figure. 1). The free proton frequency is $14.87 \mathrm{MHz}$

Figure 4: EIE spectra from partially deuterated crystals of Rochelle salt X-irradiated and measured at $10 \mathrm{~K}$. With reference to Figure 2, the spectra were recorded as follows: a) $B \|<b>$, ENDOR line at $47.35 \mathrm{MHz}(\mathrm{R} 1)$. b) $\mathrm{B} \|<\mathrm{a}>$, ENDOR line at $28.50 \mathrm{MHz}(\mathrm{R} 2)$. c) $\mathrm{B} \|<\mathrm{b}\rangle$, ENDOR line at $30.10 \mathrm{MHz}(\mathrm{K} 2)$.

Figure 5: EPR spectra with $\mathrm{B} \|<\mathrm{c}>$ of a Rochelle salt single crystal grown from $\mathrm{D}_{2} \mathrm{O}$ solution and irradiated at $12 \mathrm{~K}$ after temperature annealing as indicated directly on each spectrum. 
Figure 6: Structure of the $\mathrm{O}_{4}$-protonated one-electron reduced tartrate radical, $\quad{ }^{-} \mathrm{HOOC} \dot{\alpha}^{-}$ $\mathrm{C}_{\beta} \mathrm{H}(\mathrm{OH})-\mathrm{C}_{2} \mathrm{H}(\mathrm{OH})-\mathrm{C}_{1} \mathrm{OO}^{-}$predicted by DFT geometry optimisation. The unpaired electron density is localised to the $\mathrm{C}_{4} \mathrm{OOH}$ group. An intramolecular hydrogen bond is indicated.

Figure 7: Structure of the tartrate one-electron oxidized radical decarboxylated at $\mathrm{C}_{3}$, ${ }^{-} \mathrm{OOC}_{1}{ }^{-}$ $\mathrm{C}_{\beta} \mathrm{H}(\mathrm{OH})-\dot{\mathrm{C}}_{\alpha} \mathrm{H}(\mathrm{OH})$ as predicted by DFT geometry optimisation. The unpaired electron density is localized to the $\mathrm{C}_{3}$ atom. An intramolecular hydrogen bonds is indicated.

Figure 8: Structure of the tartrate one-electron oxidation product partly decarboxylated at $\mathrm{C}_{2}$, $\mathrm{O}_{2} \mathrm{C}_{1} \cdots \dot{\mathrm{C}}_{\alpha} \mathrm{H}(\mathrm{OH})-\mathrm{C}_{\beta} \mathrm{H}(\mathrm{OH})-\mathrm{C}_{4} \mathrm{OO}^{-}$, as predicted by DFT geometry optimisation. The unpaired electron density is localised to the $\mathrm{C}_{2}$ atom. Two of the water molecules of the cluster have been removed from this figure to enhance clarity.

Figure 9: Optimized structure of the radical formed from the $\mathrm{O}_{4}$-protonated anion by $\beta-\mathrm{OH}$ elimination, ${ }^{-} \mathrm{OO}_{1} \mathrm{C}-\mathrm{C}_{\beta} \mathrm{H}(\mathrm{OH})-\dot{\mathrm{C}}_{\alpha} \mathrm{H}-\mathrm{C}_{4} \mathrm{OO}^{-}$as predicted by DFT geometry optimisation. 


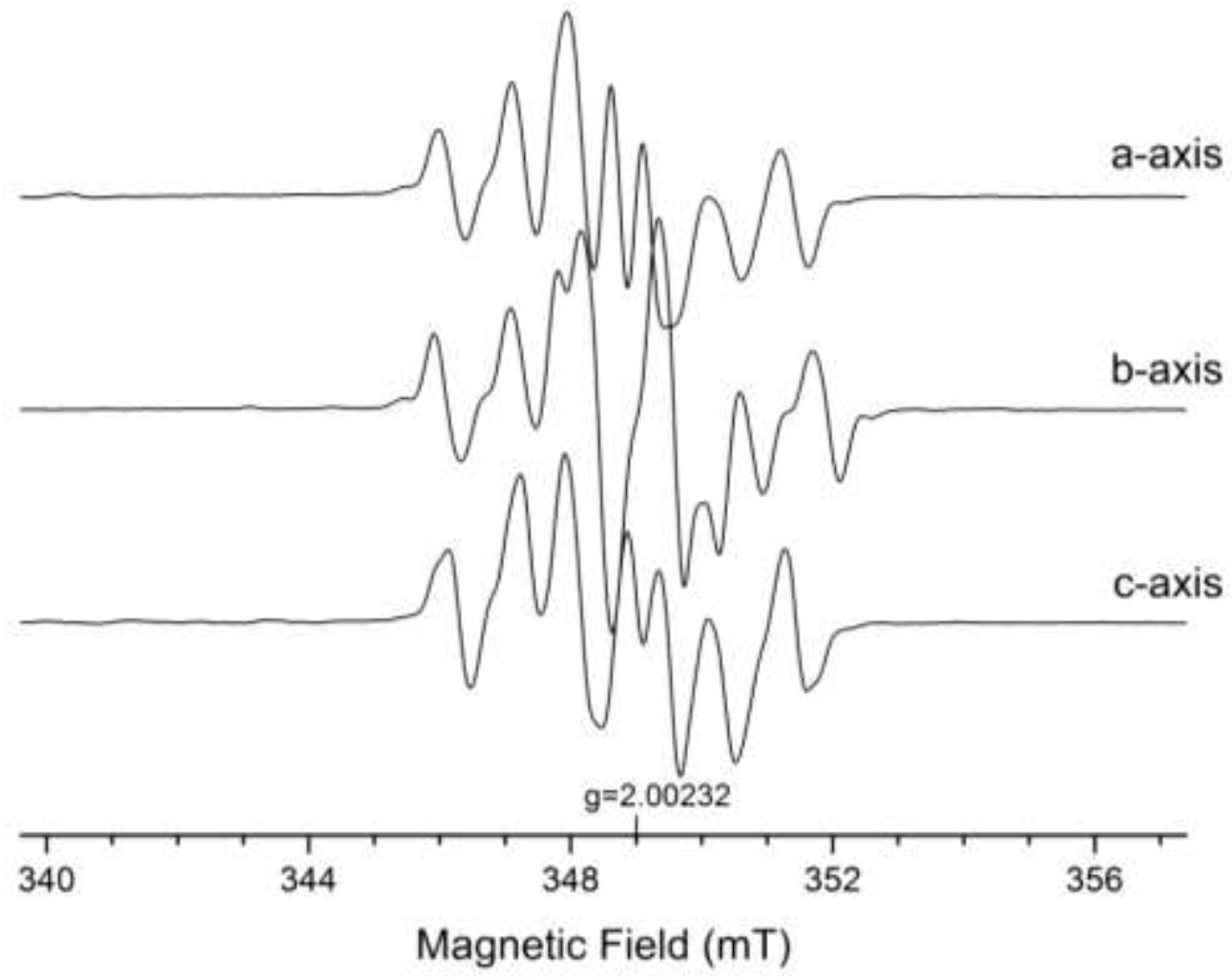

Figure 1 


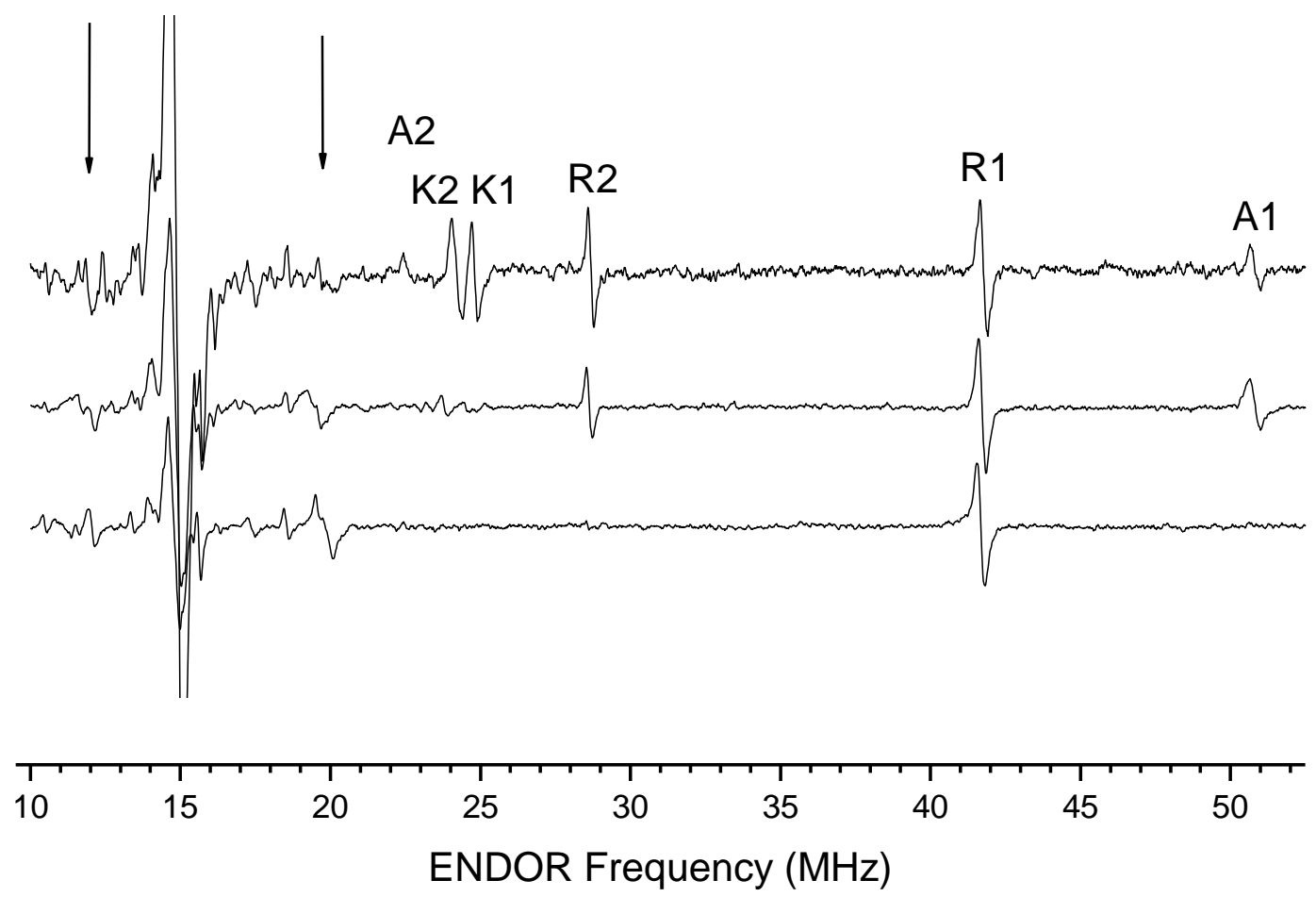

Figure 2 


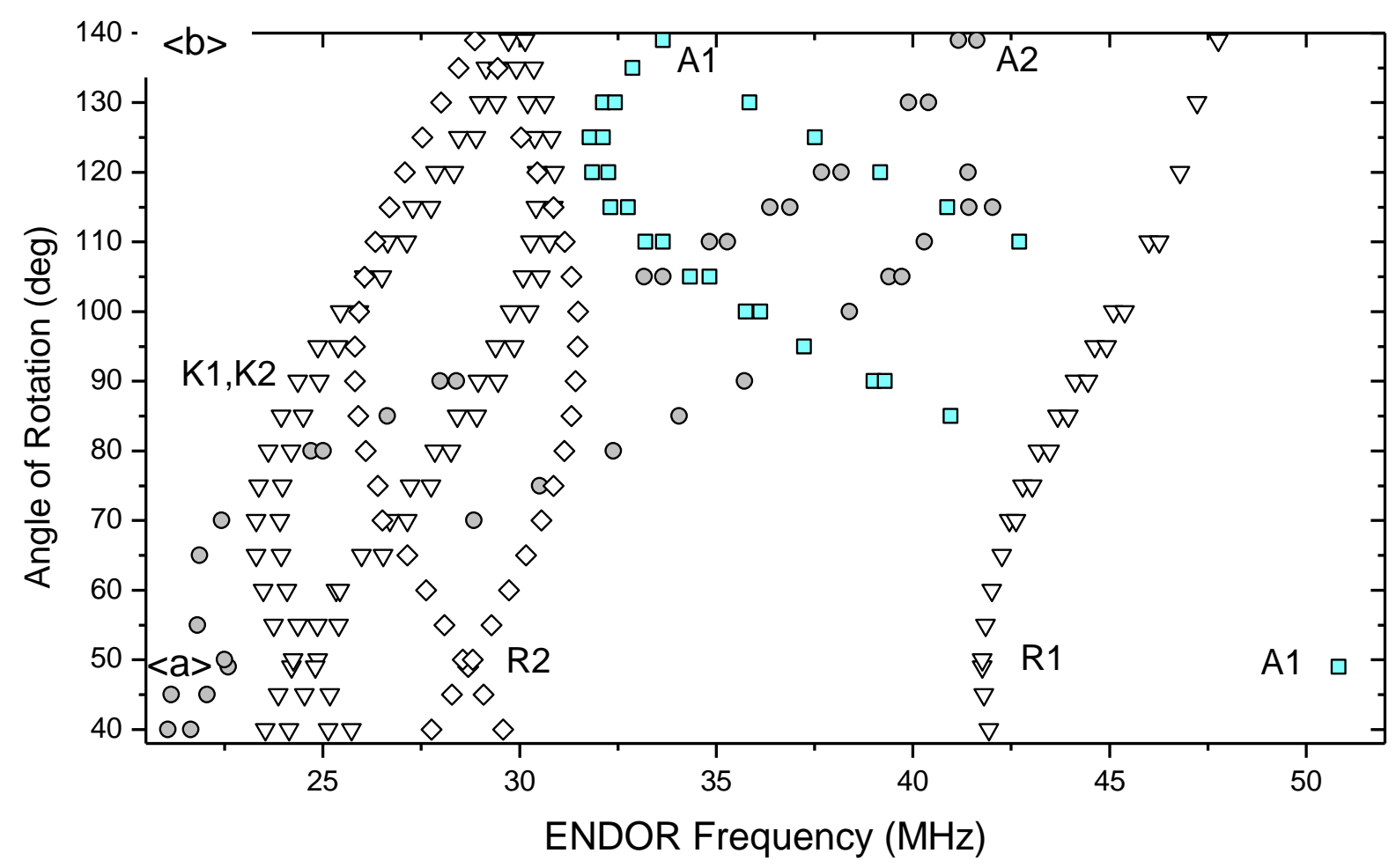

Figure 3 


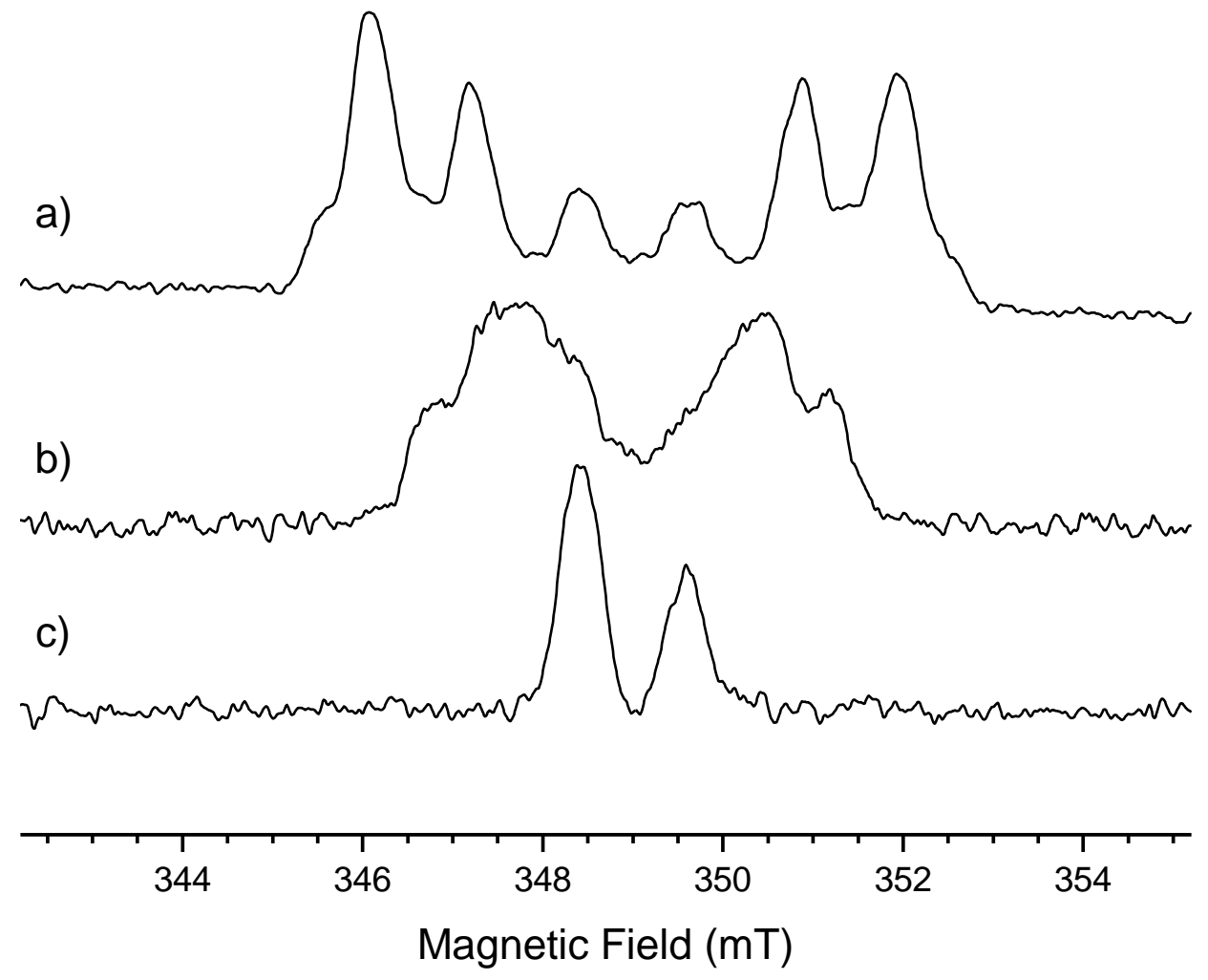

Figure 4 


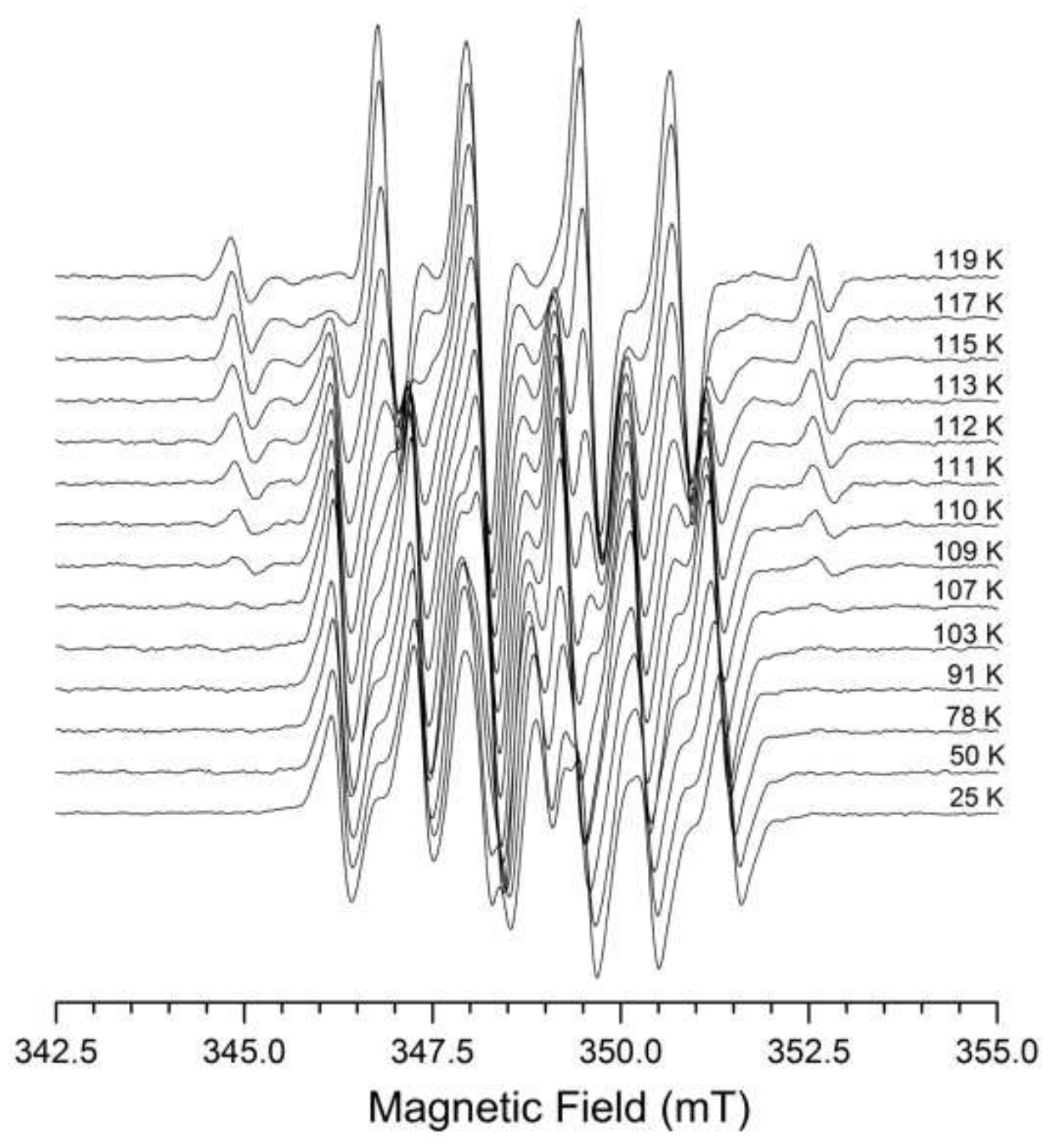

Figure 5 


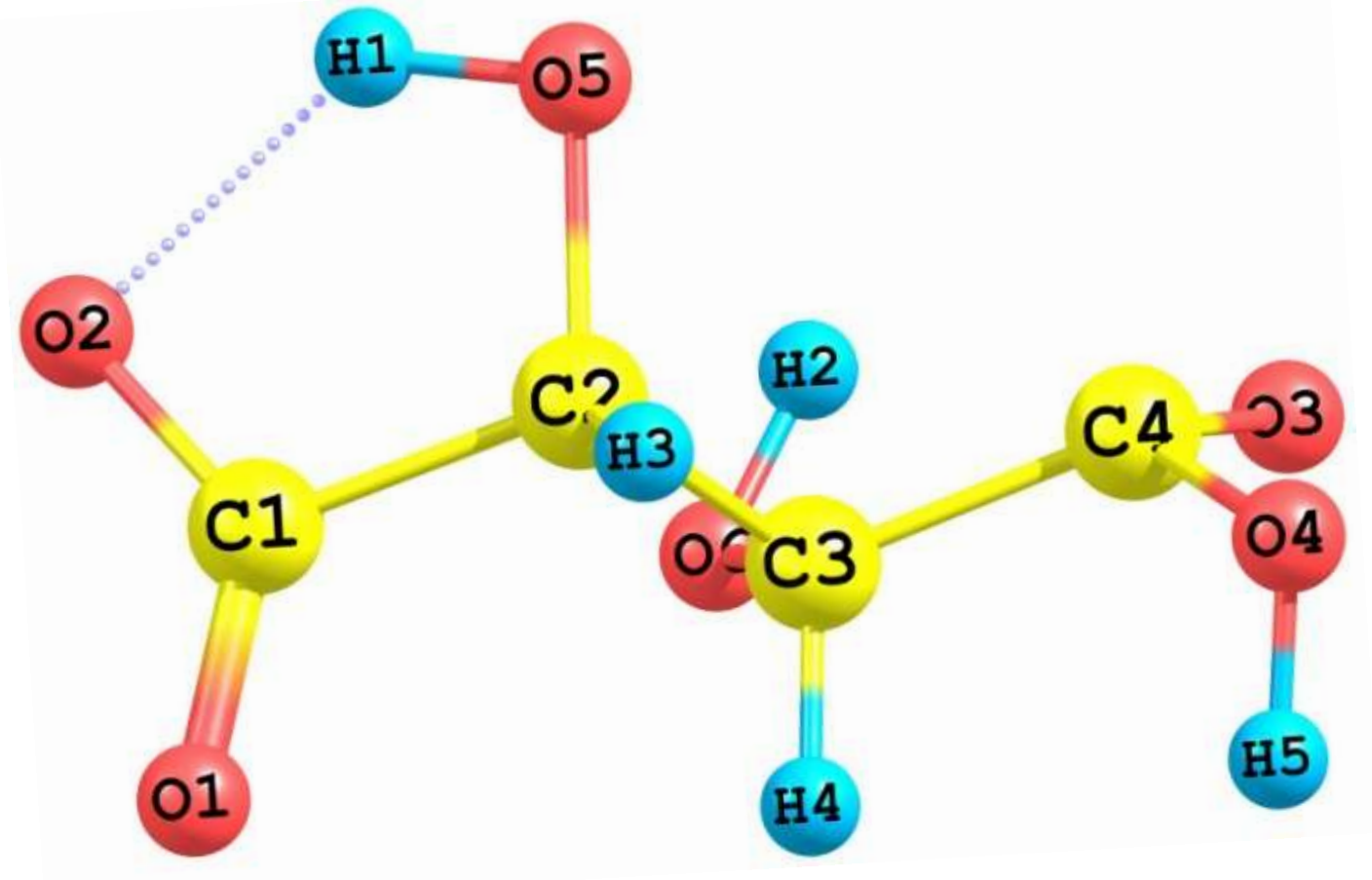

Figure 6 


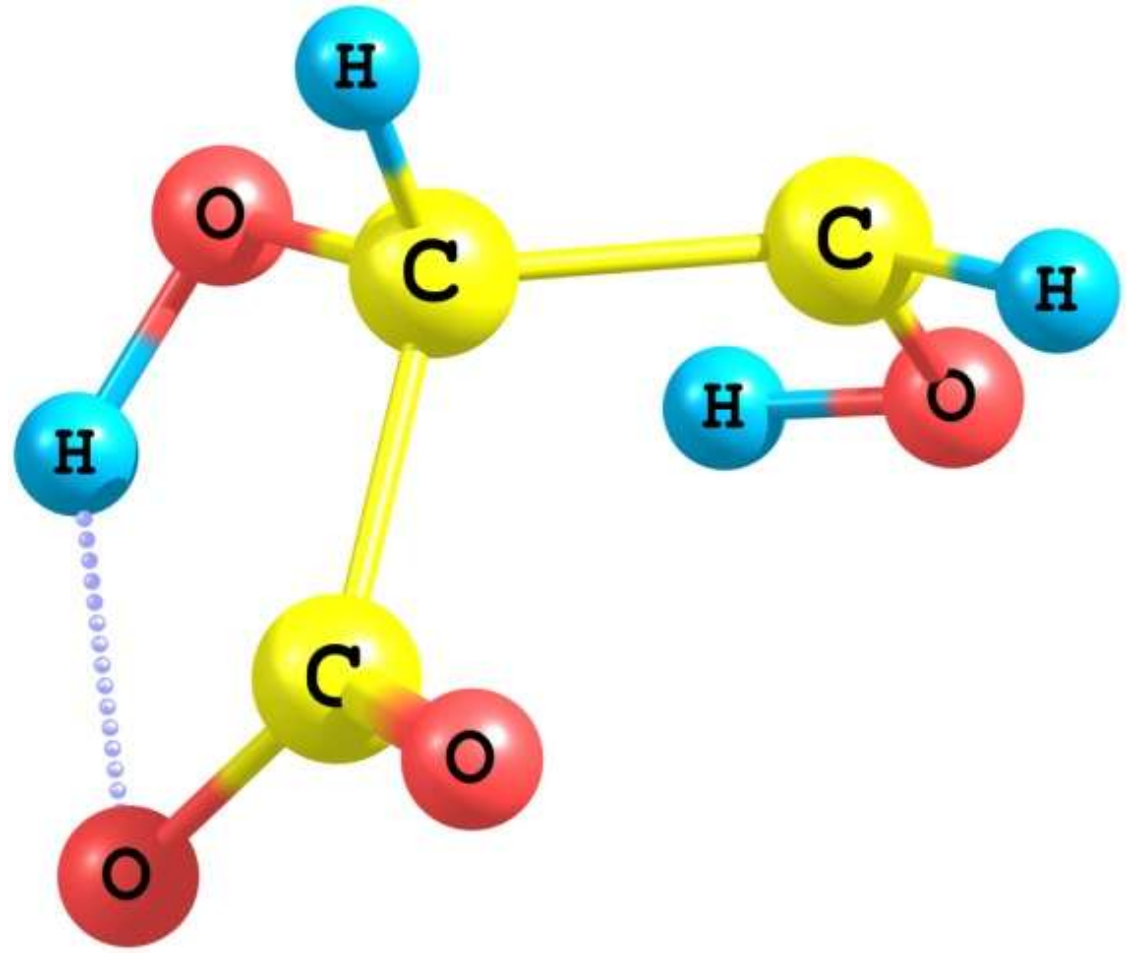

Figure 7 


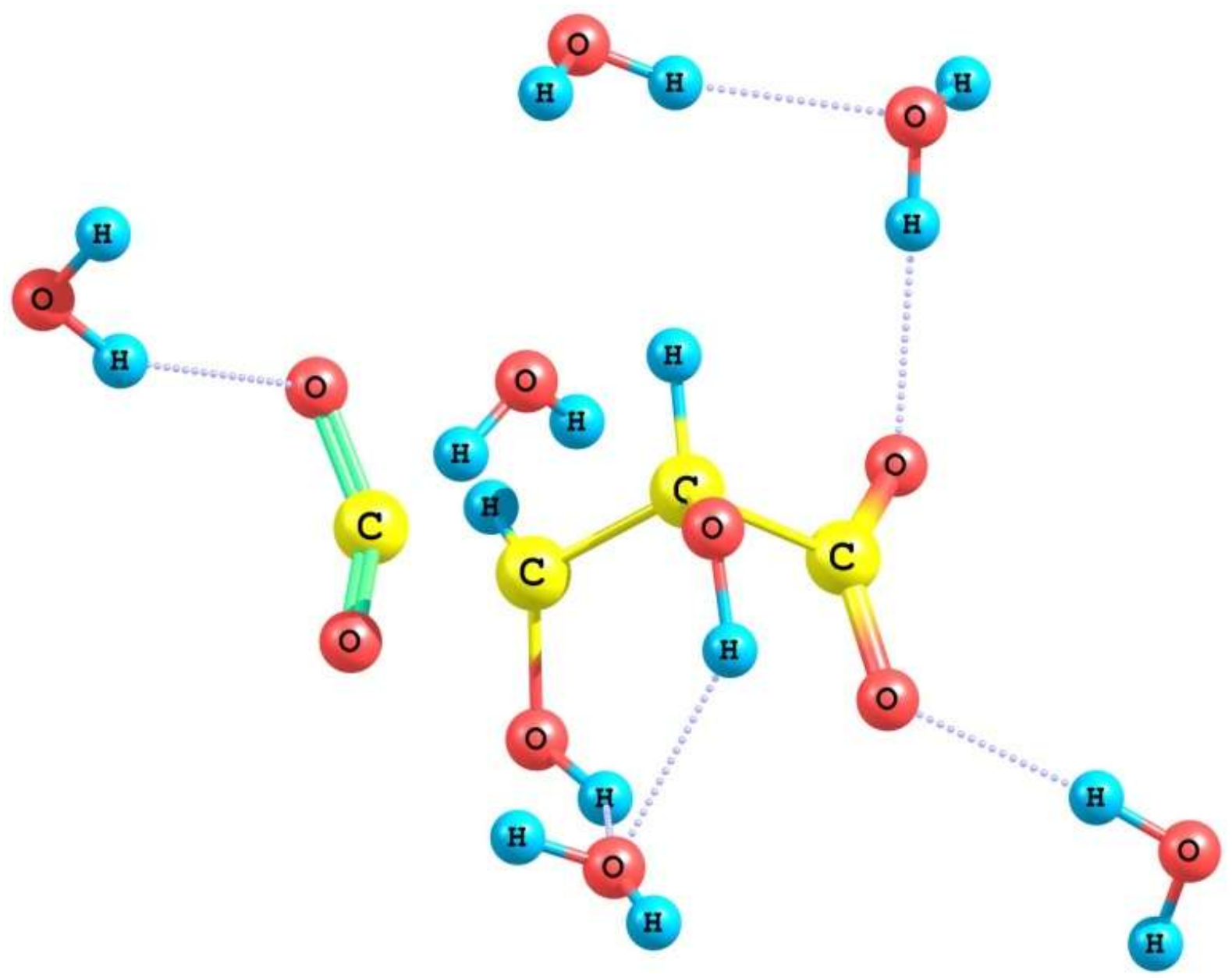

Figure 8 


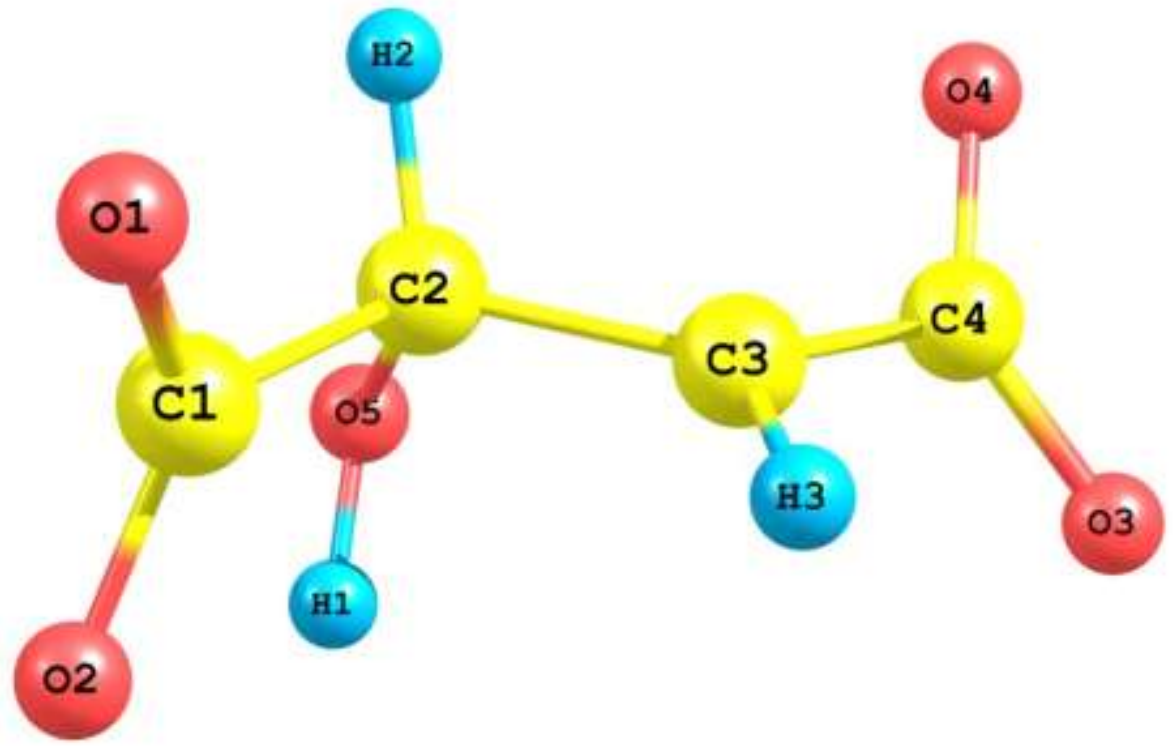

Figure 9 